\title{
Carbon-based nanomaterials engineered cement composites: a review
}

\author{
Dong L Lu ${ }^{1,2}$ and Jing Zhong ${ }^{1,2^{*}}$
}

\begin{abstract}
Carbon-based nanomaterials (CNMs) have been extensively used to modify cement matrix thanks to their extraordinary specific surface area, high aspect ratio, and high strength and modulus. This review focuses on the current status of research on CNMs modified cement composites, especially the progress made in the past decade (from 2011 to 2021). At first, the primary properties of typical CNMs used for manufacturing cement composites, the treatments used to effectively disperse CNMs in water and cement matrix, and the corresponding characterization methods are reviewed. And then, the effects of introducing CNMs on the properties of cement composites (both fresh and hardened) are also discussed in this work. Finally, the knowledge gaps and remaining challenges for future work are discussed.
\end{abstract}

Keywords: Cementitious composites, Carbon-based nanomaterials, Dispersion, Cement hydration, Rheology properties, Reinforcing mechanisms

\section{Introduction}

Cement concrete is the most widely used man-made material in modern civil engineering because of the low cost and long service time [1-3]. Typically, it is regarded as a type of material with high compressive strength and durability $[4,5]$, however, the inherently quasi-brittle behavior (e.g., poor tensile strength and crack propagation) has limited its structural applications [6-9]. Furthermore, the cement or concrete industry is high energy consumption and has a substantial environmental footprint $[3,10]$. It has been reported that the global cement production was around 4.5 billion tons and the $\mathrm{CO}_{2}$ emission was reached be approximately $1.45 \mathrm{Gt}$ in 2019 $[3,11]$. In 2020, the energy consumption of the cement industry in China was estimated at approximately 349.4 tons $[10,12]$. These years, attempts have been adopted to develop high-performance concrete or low-carbon cementitious materials [12-14], such as partially replacing cement with supplementary cementitious materials

\footnotetext{
*Correspondence: zhongjing@hit.edu.cn

1 School of Civil Engineering, Harbin Institute of Technology, 73 Huanghe

Road, Harbin, Heilongjiang 150090, P. R. China

Full list of author information is available at the end of the article
}

(SCMs) $[13,15]$, the application of some new cementitious binders $[9,16]$, and using nanomaterials to modify cement matrix $[5,17]$, etc. Among them, the ultra-fine particles-nanomaterials, show great potential to increase the density of microstructure and finally improve the mechanical and durability properties of cementitious composites.

Advancement in nanotechnology and nanomaterials over the past decade has provided invaluable opportunities to improve the microstructure of cementitious composites at the nanoscale $[5,18]$. Typically, the introduction of nanomaterials at a very small dosage can result in a significant improvement in the performance (e.g., mechanical, chemical resistance, and transport properties, etc.) of cement-based materials [12, 19, 20], with mechanisms of nano-filling $[21,22]$, nucleation effect [23, $24]$, and pozzolanic reactivity $\left(\right.$ nano- $\left.\mathrm{SiO}_{2}\right)[25,26]$, etc. Carbon-based nanomaterials (CNMs), including carbon nanotubes (CNTs) [27, 28], carbon nanofibers (CNFs) [29, 30], graphene [31], and graphene oxide (GO) [32], are very promising candidates as additives in the cement matrix [24, 31,33-35], which are abundant in nature and have already achieved industrialized mass production. 
For instance, the annual production of typical CNTs in China is approximately 500,000 tons. Currently, the price of CNTs is in the range of $80-120 \mathrm{RMB} / \mathrm{kg}$, depending on the quality and number of walls, while the prices of graphene and GO are expected to be in the range of 400$450 \mathrm{RMB} / \mathrm{kg}$ and $350-400 \mathrm{RMB} / \mathrm{kg}$ in near future, respectively (http://www.nanotubes.com.cn.). Generally, the addition amount of CNTs, graphene, and GO (by weight of cement) are 0.01-0.15 wt\% [30], 0.01-2.5 wt\% [36], 0.01-1.0 wt\% [37], respectively. As such, it can be estimated that the addition of $0.01 \mathrm{wt} \% \mathrm{CNTs}$, graphene, and GO could increase the cost per ton of cement in concrete production by approximately 8-12 RMB, 40-45 RMB, and 35-40 RMB, respectively. According to the published literature, the addition of $0.01 \mathrm{wt} \%$ GO can increase the 28-d compressive strength of cement composites by about 20-30\% [37], thus, it can be estimated that the cost of cement reduces by approximately $130 \mathrm{RMB} /$ ton for equivalent strength (the strength of $\mathrm{GO} /$ cement- 42.5 has roughly the same strength with cement-52.5), more than enough to cover the expense for GO addition. This could trigger a substantial economic benefit and alleviate the undesirable impacts of $\mathrm{CO}_{2}$ emission on the ecological environment.

Unfortunately, although the application of CNMs showed great potential in cement modification, their broad application is still limited due to the poor dispersion quality, as well as the controversial understanding of the effects of CNMs on cement hydration [20, 24, 27]. Additionally, basic mechanisms for cement reinforcement of these CNMs are still under debate $[20,22,24,38$, $39]$. To this end, it is urgent to review the current knowledge related to the use of CNMs in cement composites and accelerate their practical applications. It is believed that these gaps fundamentally stem from the failure to thoroughly address the following questions: (i) how to quantitatively assess the dispersion quality of CNMs in a cement matrix; And (ii) what types of CNMs have nucleation effect and significantly affect cement hydration. In this context, the properties of CNMs used in cement materials are introduced at first. Then the different dispersion methods employed to manufacture cement composites and the current evaluation methods are summarized. Next, we discuss the hydration and rheological properties of a fresh mixture for a better understanding of the influence of admixed CNMs in a cement hydration system. Finally, the influences of CNMs on the mechanical and durability properties of hardened cement composites are reviewed.

\section{Properties of CNMs and their morphology}

In this review work, we only discussed one-dimensional (1D) nanofibers (CNTs and CNFs) and two-dimensional (2D) nanosheets (graphene and GO), the properties of which are presented in Table 1 and Fig. 1, because they are the most studied CNMs in enhancing cement materials during the last decade [19, 20, 50-54].

CNT (or CNTs) has a 1D concentric tubular structure with a hexagonal arrangement of carbon atoms and they were firstly reported by Iijima in 1991 [55]. The quality, property, and production of CNTs were continuously improving since then. The diameter and length of CNTs are typically in the range of 1-100 $\mathrm{nm}$ and 1-100 $\mu \mathrm{m}$, respectively, resulting in a very high aspect ratio and thus severe entanglement with each other [56-58]. These physical crosslinking, together with Van der Waal's interaction between CNTs, making their dispersion very challenging in water or cement matrix $[28,59]$. It is well known in the CNTs community that, for a given dispersion method, the dispersion quality is highly dependent on the CNTs tortuosity and aspect ratio, both of which largely determine the entanglement degrees [59, 60].

Table 1 The primary properties of CNMs used for preparing cement composites

\begin{tabular}{|c|c|c|c|c|}
\hline Component & CNTs & CNFs & Graphene & GO \\
\hline \multirow[t]{2}{*}{ Diameter/thickness (nm) } & $0.4-2.0(\mathrm{SWCNTS})^{\mathrm{a}}$ & $0.5-100$ & $\sim 1$ & $\sim 0.67$ \\
\hline & $1.0-100$ (MWCNTs) $^{\mathrm{a}}$ & & & \\
\hline Aspect ratio & $1000-10,000$ & $100-1000$ & $600-600,000$ & $1500-45,000$ \\
\hline $\mathrm{SSA}^{\mathrm{a}}\left(\mathrm{m}^{2} / \mathrm{g}\right)$ & $20-1315$ & $100-1000$ & $700-1500$ & $2000-2600$ \\
\hline Elastic modulus (GPa) & $>1000$ & $6-200$ & $>1100$ & $>300$ \\
\hline Tensile strength (GPa) & $50-200$ & $400-600$ & $\sim 125$ & $>112$ \\
\hline Resistivity $(\Omega \cdot \mathrm{cm})$ & $\sim 10^{-2}$ & 0.1 & - & - \\
\hline Thermal conductivity $\mathrm{W} /(\mathrm{m} \cdot \mathrm{K})$ & $\sim 6600$ & $20-1950$ & - & - \\
\hline Special applications & \multicolumn{2}{|c|}{ For structural health monitoring $[28,40-43]$. } & $\begin{array}{l}\text { Electromagnetic protection } \\
{[31,44,45] \text {. }}\end{array}$ & $\begin{array}{l}\text { Accelerating cement } \\
\text { hydration }[20,24,39 \text {, } \\
46] \text {. }\end{array}$ \\
\hline
\end{tabular}

${ }^{a}$ SWCNTs and MWCNTS are single-wall CNTs and multi-walled CNTs, respectively. SSA is a specific surface area 


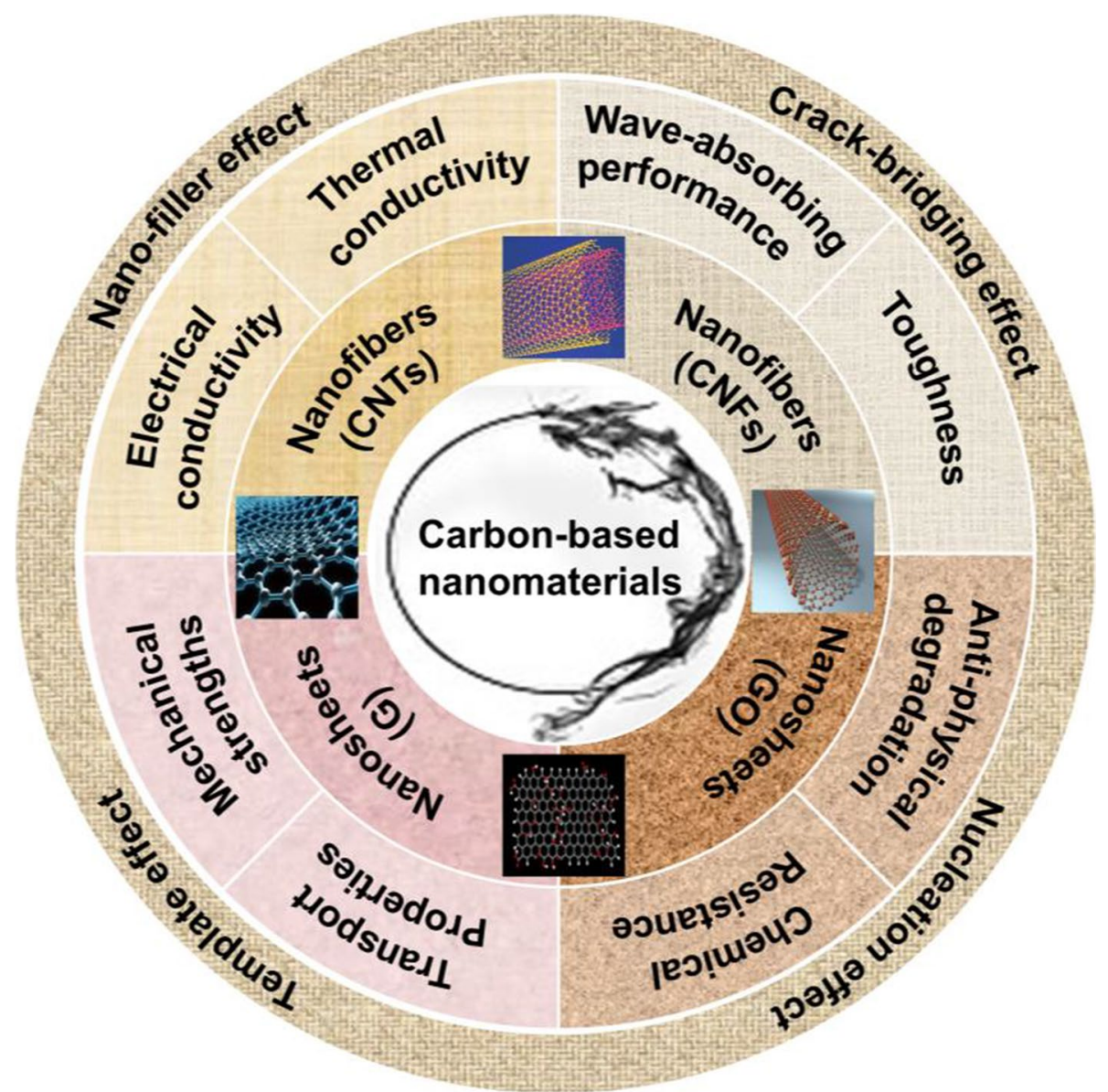

Fig. 1 The roles of the typical 1D nanofibers (CNTs and CNFs) and 2D nanosheets (graphene and GO) in cement composites [19, 22, 28, 34, 39, 45, 47-49]. G represents graphene

CNFs are cylindrical nanostructures with graphene layers arranged as stacked cones, which can be viewed as fiber-shaped nanomaterial with a length ranging from $50 \mathrm{~nm}$ to $200 \mathrm{~nm}[45,61]$. CNFs have similar geometrics and physical properties with CNTs, yet with much lower price (generally one-fifth of the price of CNTs), and thus also extensively employed as an additive for cement matrix modification [30,62]. Owing to the potential micro (and nano) improvement of the interfacial transitional zone (ITZ), CNFs demonstrate a great potential to improve the mechanical strengths of cement materials [34]. Additionally, CNMs (especially graphene, CNTs, and CNFs) demonstrate great potential to develop smart cement composites in the future.

Strictly speaking, graphene is a one-atom-thick flat nanosheet of $\mathrm{sp}^{2}$ bonded carbon atoms, it is arranged in a honeycomb-like lattice [63-65], which is the mother of all graphitic materials, such as fullerenes, CNTs, and graphite $[64,66]$. Note that, most of the excellent physicochemical characteristics of graphene, such as excellent strength, high modulus, and outstanding electrical conductivity, are in-plane properties, essentially resulted from the in-plane $\mathrm{sp}^{2}$ carbon-carbon bonds [63, 67] Interestingly, because of the extremely small thickness of graphene, it can also be considered to be soft matter. According to the previous reports, GO has a similar bending stiffness with graphene (assuming a similar thickness), is in the order of $2 \mathrm{kT}[63,68,69]$, meaning that these single-layer $2 \mathrm{D}$ materials can be easily buckled and a considerable amount of wrinkles will be naturally formed $[63,64,66]$. Such features could affect the interaction between graphene (and its derivatives) with matrix materials [36, 59, 70, 71]. Because single-layer graphene with atom thickness and perfect crystal structure, which cannot be yielded at a large scale currently, the commercially available materials claimed as "graphene" are actually multi-layers thin graphite [63, 64, 68]. They are mostly synthesized by exfoliation of graphite either by intercalation followed by mechanical shearing [63, 64, 72]. According to classical plate theory, the bending 
stiffness of plates is inversely proportional to the cubic thickness [63-65]. Implying that the bending stiffness of multi-layer graphene with $\sim 30 \mathrm{~nm}$ (corresponding to 100 layers), which is six orders of magnitude higher than that of the single-layer graphene $[63,64,68,72]$. Such huge different bending stiffness could significantly change graphene-cement interactions.

Another strategy to synthesize graphene is to chemically reduce GO [64, 73, 74], which can be readily obtained by oxidation of graphite in strong acid, as firstly reported more than a century ago [64, 68, 72, 74]. Fig. 2 illustrates the GO synthesis process. In short, the gap between adjacent layers in graphite greatly increased due to the functionalization of graphene, mainly by carboxylate and epoxy groups, thus effectively decreased Van der Waal's interaction between graphene layers, allowing easy exfoliation into single layers in water $[64,65]$. Therefore, single-layer GO dispersion with high quality was easy to prepare. More importantly, its oxygen-containing functional groups fancy involving chemical/physical interactions [20, 24, 75], and then enhancing the bond strength $[73,76]$. Based on these characteristics, it has been generally accepted that GO can accelerate cement hydration $[20,53,75,77,78]$, improve the polymerization degree of cement hydrates [20, 24], and regulate the formation of hydration crystals [46, 79, 80]. With these advantages, GO has been the most studied CNMs for the modification of cement materials during the past decade (as depicted in Fig. 3).

\section{Dispersion and characterization of CNMs in water and cement matrix}

\section{Challenges for CNMs dispersing}

As mentioned above, the possible agglomeration of $\mathrm{CNMs}$ in the cement matrix are defects and negatively affect the properties of cement composites [19, 28, 53, 81-83]. That is, a high dispersion quality of CNMs is a prerequisite for the effective reinforcement of cementbased materials $[8,44]$. However, it is still very challenging to realize an excellent dispersion of CNMs in the cement matrix, since the strong Van der Waal's attraction between CNMs, as well as the complex electrolytic environment provided by cement pore solution (in the presence of divalent ions) [29, 82, 84, 85].

Table 2 summarizes the dispersion methods of CNMs in the water and cement matrix. According to the published literature, acid treatment and surfactant wrapping are generally the most used strategies to overcome

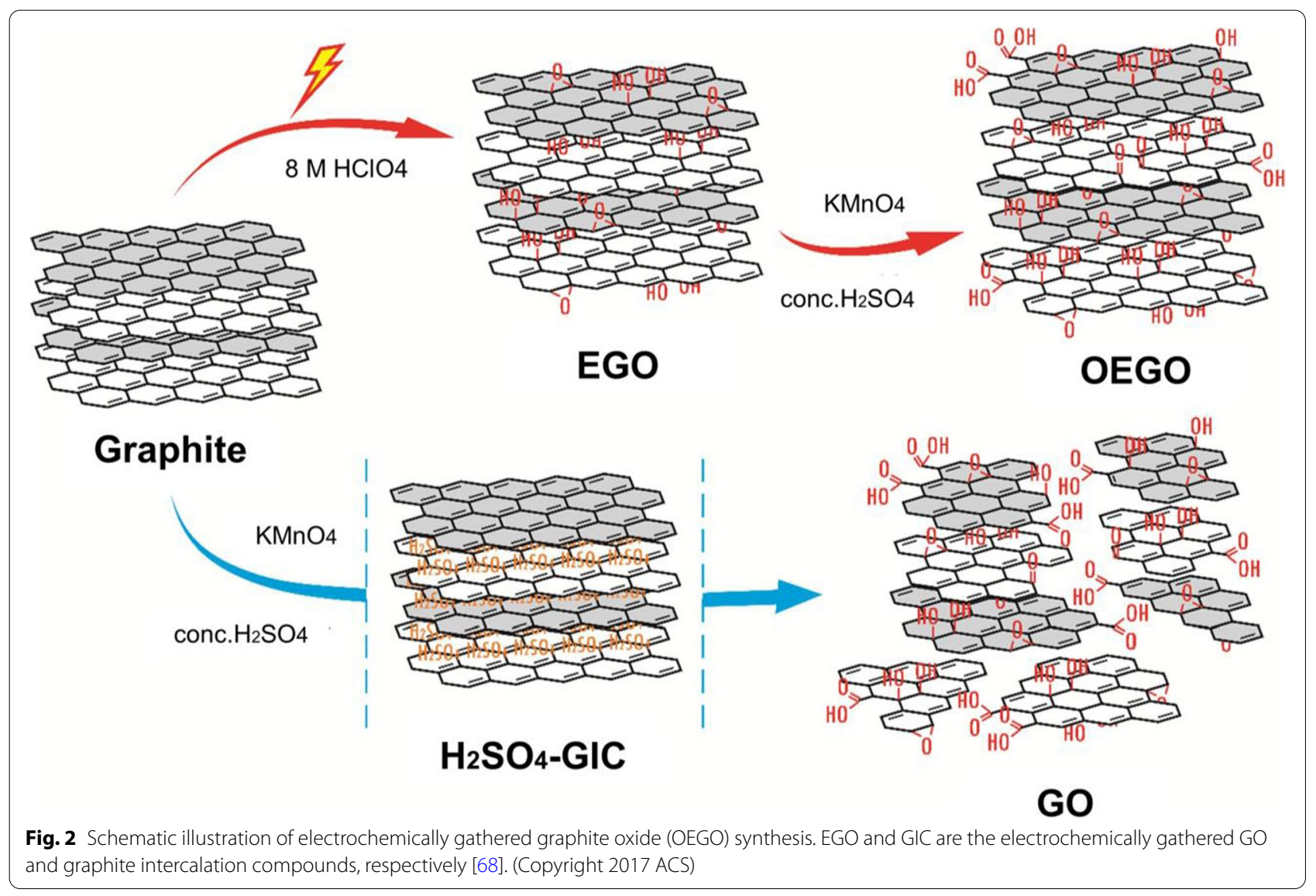




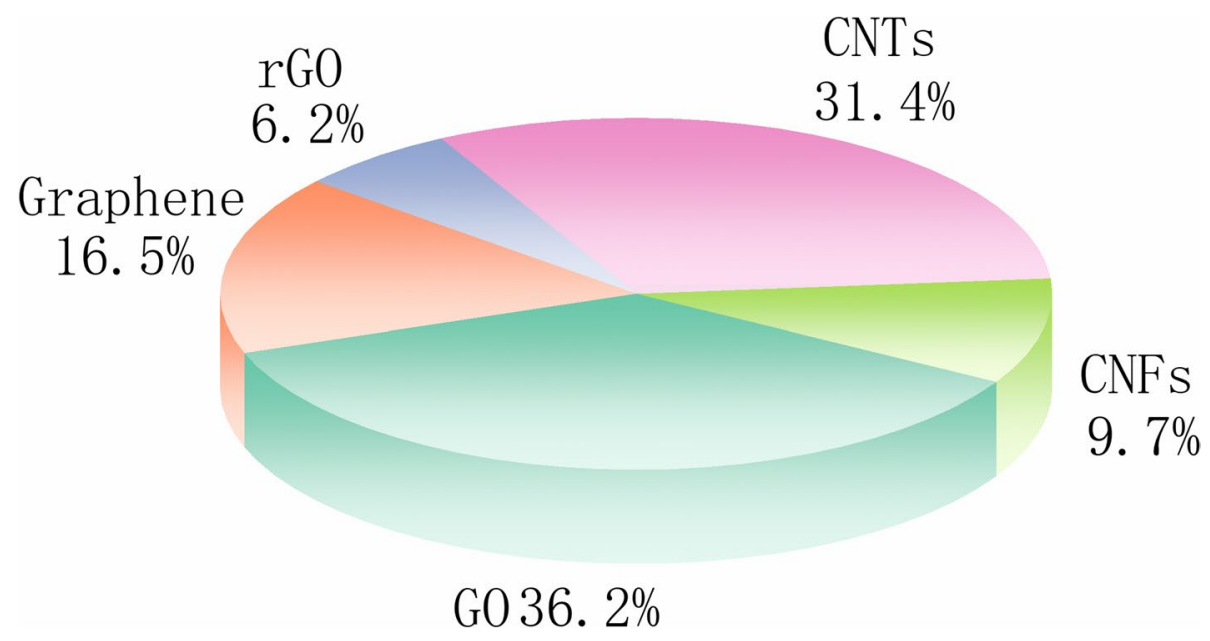

Fig. 3 The relative number of published articles of various CNMs used for manufacturing cement composites, rGO is reduced GO. (Data collected from Google Scholar from 2011 to 2021, total of 14206 published literature)

Table 2 Dispersion methods of CNMs in water and cement matrix

\begin{tabular}{|c|c|c|c|c|}
\hline Dispersion methods & & System & Description & Ref. \\
\hline Ultrasonic dispersion & & Water & Ultrasonic waves/energy can cavitate and exfoliate the CNMs. & {$[28,86,87]$} \\
\hline Acid treatment & & Water & The strong steric hindrance effects can separate CNMs from & {$[38,65]$} \\
\hline Surface modification & & $\begin{array}{l}\text { Water/cement } \\
\text { pore solution }\end{array}$ & charged ions. & {$[82,84,85,88]$} \\
\hline Mechanical dispersion & $\begin{array}{l}\text { Mechanical agitation } \\
\text { Ball milling }\end{array}$ & Cement matrix & $\begin{array}{l}\text { Applying shearing force created by mechanical friction, colli- } \\
\text { sion, and crush on CNMs. }\end{array}$ & $\begin{array}{l}{[19,51,89-91]} \\
{[52,92,93]}\end{array}$ \\
\hline Integrated dispersion method & & Cement matrix & The combined usage of the aforementioned methods. & {$[21,22]$} \\
\hline Silica fume or nano-silica & & Cement matrix & Using spherical particles to prevent agglomeration of CNMs. & {$[84,85,94-97]$} \\
\hline
\end{tabular}

attractions between CNMs [52, 82, 85, 88, 92]. Specifically, acid can endow charges on the surface of CNMs at the cost of some detrimental effects on their structure [65], while surfactant wrapping can make CNMs more compatible with water, with the mechanism of either charge repulsion or steric repulsion depending on the molecular structure of surfactant $[29,82,85,88]$. However, the high ionic concentration of cement pore solution (high alkalinity and di-covalent $\mathrm{Ca}$ ions), could severely screen charge repulsion interaction [84, 98]. Therefore, considering the highly complex electrolyte environment of pore solution in cement hydration, the achievement of uniform dispersion of CNMs in cement matrix is still very challenging. Since CNMs are typically dispersed in water before mixing with cement, this review work summarized CNMs dispersion in water, cement pore solution, and cement matrix, separately, to clarify the main mechanism and related colloidal behavior in each step.

\section{Dispersion of CNMs in water}

At present, admixtures are indispensable constituents in modern cement concrete applications $[5,12,36,37,44$, 99]. Surface active chemicals, including superplasticizers, shrinkage reducing admixtures, and air-entraining surfactants, etc., are prepared in the form of an aqueous solution before mixing with cement powder $[82,84,85$, 100]. Along with this idea, the preparation of uniform aqueous dispersion of CNMs can facilitate their practical applications $[9,101]$.

Currently, the dispersion methods of CNMs in water mainly include mechanical shearing and ultrasonication, and surface physiochemical modification $[19,91]$, as presented in Table 2. For a given material, the dispersion capability of shearing is mainly dependent on the shearing stress, which in turn, are determined by the shearing rate and viscosity of the dispersion [51, 52, 89]. Since the viscosity of CNMs dispersion is typically in the same range of water [102], the maximum shearing 
stress and dispersion quality that can be realized is very limited. Ultra-sonication is a process based on cavitation (about $200 \mathrm{~W}$ and the frequency of $30 \mathrm{kHz}$ ), with high local energy, and has been extensively employed for CNMs dispersion [21, 22, 28]. The effectiveness of ultra-sonication can be optimized by a proper combination of sonication power and sonication time [19, 21, $22]$. Note that, because of the high cavitation energy, the crystal structure and aspect ratio of CNMs may be destroyed and reduced, both of which will decrease the reinforcement efficiency of CNMs [22, 99]. Besides, for a given material and sonication power, the dispersion quality will be saturated with time, as reported by Coleman et al. [103]. Therefore, proper optimization of sonication conditions is required to further promote the dispersion quality of CNMs.

To further promote the dispersion quality, CNMs can be grafted with hydrophilic functional groups, both physically and chemically $[81,82]$. GO, which has been extensively used to modify cement matrix past the last decade [20, 24, 77, 82, 104, 105], can be considered as graphene that is chemically grafted with a significant amount of oxygen-containing groups [64]. CNTs treatment by strong acid is also commonly used to facilitate its dispersion in water [38, 65]. As explained above, such a dispersion method relies on the surface charge repulsion, which can be easily screened out by ions if there is any [20]. This means that even CNMs can be well dispersed in water after chemical modification, they might still agglomerate when mixed with cement, because of the high ionic strength resulted from cement dissolution.

Another surface modification method is to wrap CNMs with surfactants $[37,82,84,85,88,100]$. Broadly, the surfactants can be divided into categories of anionic [82], cation [106], and neutral type [82], all of them have been studied for CNMs dispersion. As matter of fact, organic admixtures, including water-reducing admixtures, air-entraining admixtures, superplasticizers, shrinkage reducing admixtures, are all surfactants that can be potentially employed to disperse CNMs [82, 88, 107]. Polycarboxylate superplasticizer (SP), which is currently the most used surfactant, has been extensively investigated to disperse CNMs and enhance the stability of the resulted dispersion upon increasing ionic strength [82, 85, 88, 100, 107, 108]. As illustrated in Fig. 4, using $\mathrm{SP}$ in a GO-cement system can disperse GO nanosheets and cement grains at the same time (Fig. 4a). Similarly, a good dispersion quality of graphene in an aqueous solution can be achieved with the help of SP (Fig. 4b). However, it should be noted that the absorbed surfactant itself could also be stripped off when the ionic strength is high enough [82, 110]. For instance, Zhao et al. [100] reported that the $\mathrm{GO}$ could aggregate again when the $\mathrm{Ca}$ ions concentration was reached $1 \mathrm{M}(\mathrm{NaOH}$ solution) or higher [82].

Interestingly, the stability of surfactants that are wrapped around CNMs in the various electrolyte has been systematically investigated since more than two decades ago in environmental science [80-82, 85, 111],

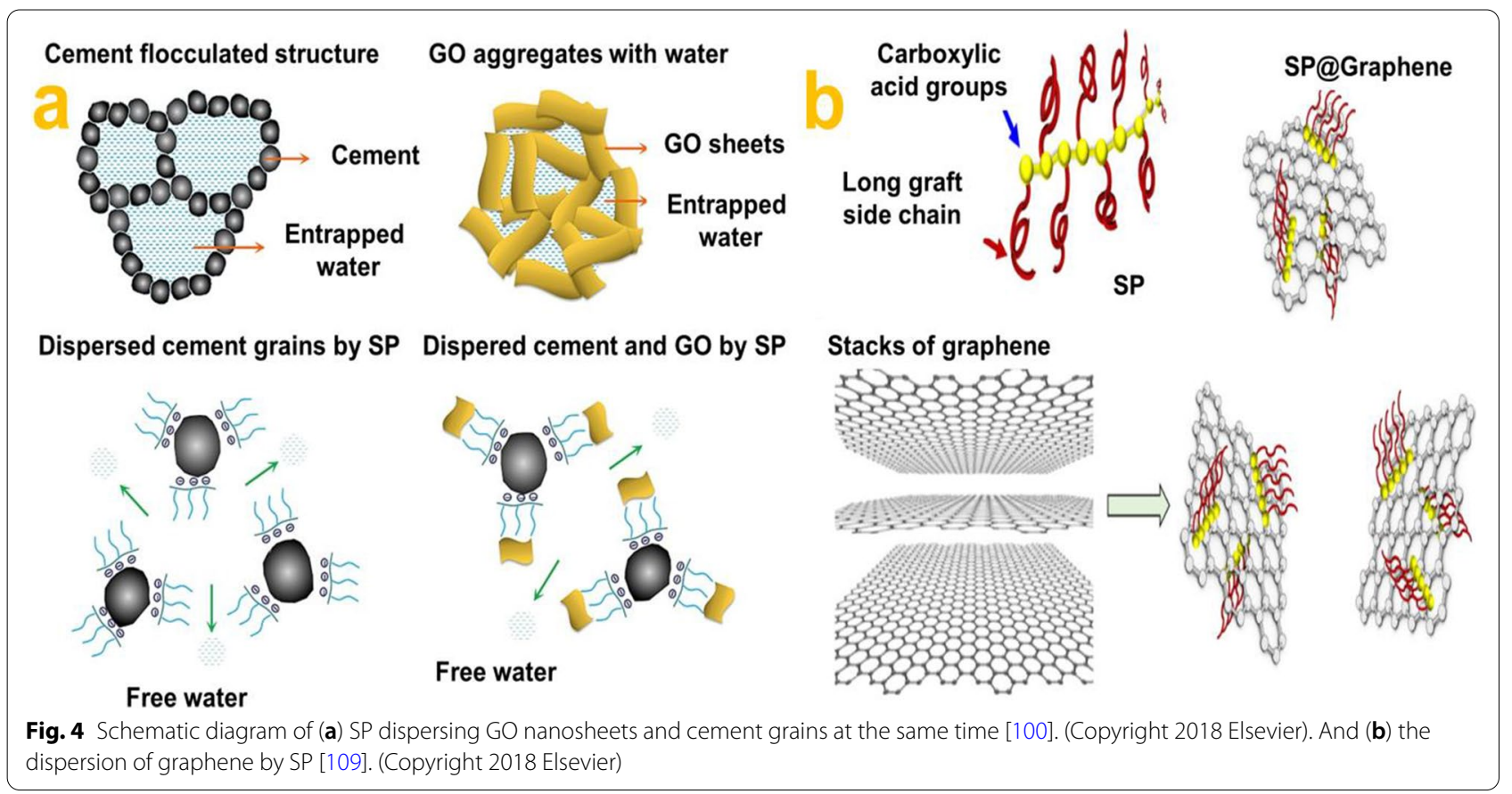


in which, the agglomeration of particles is one of the key research topics. However, the exact chemical structures of most SP are generally confidential, blurring the optimization of the CNMs dispersion. Because SP is synthesized for cement property modification through SP-cement grain interaction, a new surfactant should be designed and prepared specifically for the CNMs dispersion. Moreover, the stability of surfactants for CNMs dispersion still needs to be studied and clarified [85]. As reported by Birenboim et al. [22], the introduction of surfactants can retard the cement hydration and entrap substantial air in cement paste. It has been pointed that caution should be exercised when using surfactants in the aqueous matrix, as it can lead to foaming [12, 22]. Therefore, there might be a trade-off between the positive effects of CNMs and the negative influences of surfactants.

\section{Dispersion of CNMs in the cement matrix}

CNMs can also be considered to be an admixture in the form of dry powders, and directly mixed with cement, similar to silica fume, fly ash, and slags [19, 28, 29, 51, 89]. Typically, CNMs are mechanically mixed with cement particles for several minutes to obtain a homogeneous mixture and then mixed with water and other raw materials to manufacture cement composites [16, 20, 24]. For example, as indicated by Mohammed et al. [112],
$0.01 \mathrm{wt} \% \mathrm{GO}$ and cement were mechanically stirred for about $5 \mathrm{~min}$ to obtain a uniform mixture, while they failed to achieve good dispersion when the GO amount was $0.06 \mathrm{wt} \% \mathrm{GO}$, due to the physical cross-linking and Van der Waal's forces between GO nanosheets. It is almost impossible to dis-entanglement CNMs agglomerations just by normal shear mixing apparatus. Recently, silica fume $/$ nano- $\mathrm{SiO}_{2}$ with extremely small particle size and spherical particles, have been employed to disperse $\mathrm{CNMs}$ in the cement matrix by a pre-mixing process [84, $85,97,105,107,113]$, as illustrated in Fig. 5. Because of the high SSA of CNMs, the effectiveness of using silica fume as carriers to disperse CNMs, mainly depends on the available surface area of the carriers. For instance, Kim et al. [115] investigated the effect of silica fume content (0-30\%, mass by cement) on the dispersion of CNTs in a cement matrix, and found that $20 \mathrm{wt} \%$ silica fume and $0.3 \mathrm{wt} \% \mathrm{CNTs}$ were mixed for 4 min could facilitate the dispersion of CNTs. We can roughly estimate the maximum concentration of well-dispersed nano- $\mathrm{SiO}_{2}$ that can be realized by this strategy as follows. Assuming that the silica fume particles with a typical size of 50-300 $\mathrm{nm}$ can be well separated and completely covered by a single layer of closely compacted nano- $\mathrm{SiO}_{2}$ (with a typical size of 4-20 $\mathrm{nm}$ ), the concentration of nano$\mathrm{SiO}_{2}$ in the cement matrix could reach obtain an optimal value. Note that, this method in fact realizes a uniform

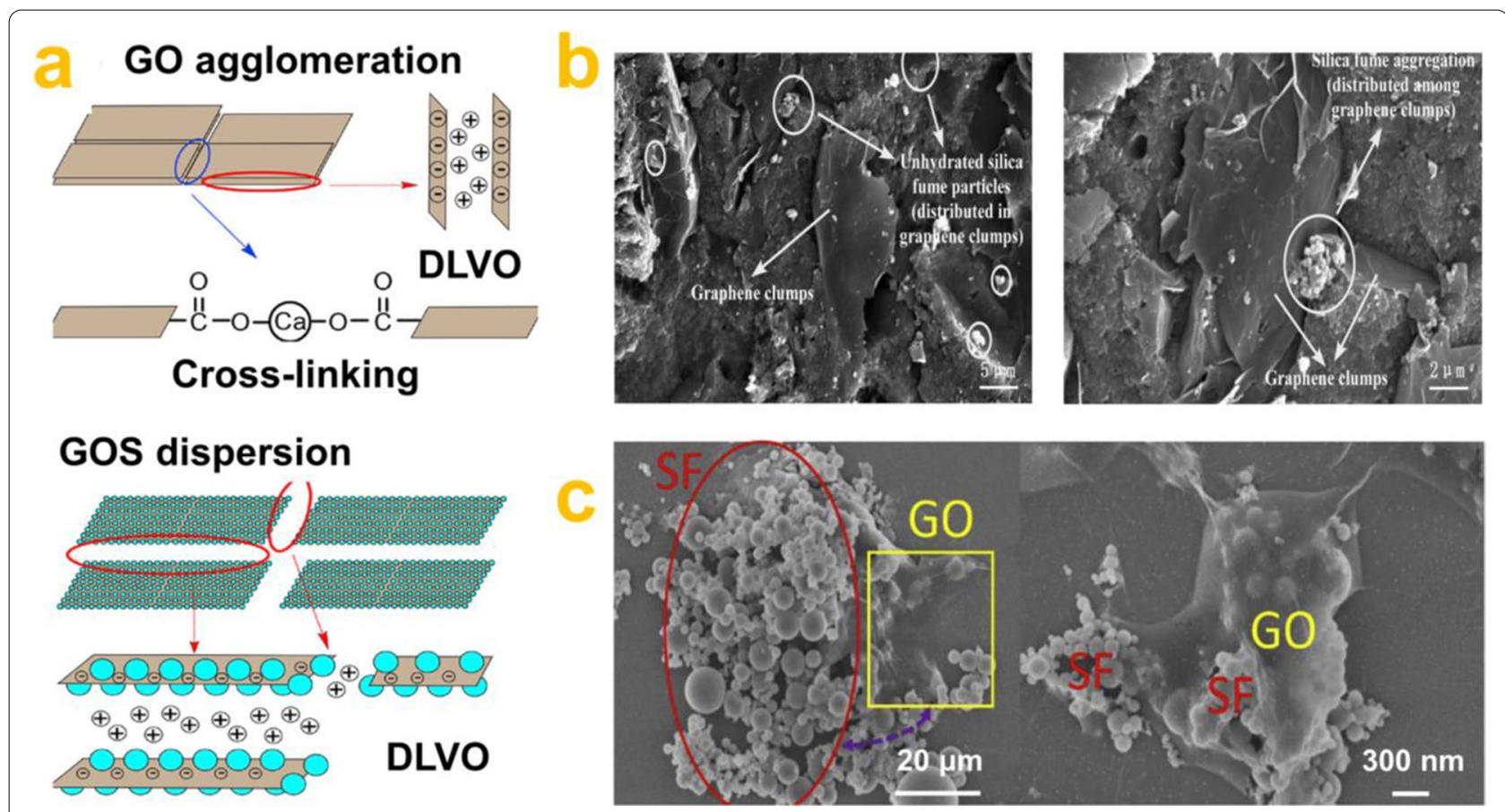

Fig. 5 Schematic of GO-SiO, nanohybrids (GOS) dispersion [105]. (Copyright 2020 Elsevier). b SEM image of the graphene-silica fume dispersion in cement matrix [114]. (Copyright 2018 Elsevier). And (c) SEM image of GO-silica fume dispersion [84]. (Copyright 2018 Elsevier) 
distribution of nano- $\mathrm{SiO}_{2}$ throughout the whole matrix, at the cost of local severe agglomeration specifically at the surface of silica fume. Therefore, such nano- $\mathrm{SiO}_{2}$ can in principle only modify the local chemistry and microstructure around silica fume. Also, the pre-mixing time of silica fume and CNMs is another key factor that affects the dispersion of CNMs in the cement matrix. For example, Akarsh et al. [94] and Bai et al. [114] pointed out the GO-cement and graphene-cement should premix for approximately $3 \mathrm{~min}$ and $10 \mathrm{~min}$, respectively, to obtain a uniform mixture. A similar pre-mixing time for nano$\mathrm{SiO}_{2}$ and $\mathrm{CNMs}$ was also reported in other studies [85, 97, 105].

To increase the shearing stress significantly, highenergy ball milling can be applied [52, 92, 93, 116]. For instance, Ghosh et al. [117] proposed that the graphene and cement grains were blended using a planetary ball mill via $30 \mathrm{~g}$ Zirconia balls, which is an efficient approach to obtain a homogenous distribution of graphene with cement grains. Jing et al. [92] used X-ray diffraction (XRD) and scanning electronic microscope (SEM) to verify this hypothesis. A similar beneficial role of ball milling on dispersion graphene was reported in another report [89], in which the graphene and cement were dry mixed for $72 \mathrm{~h}$. Chiranjiakumari et al. [118] using a high-energy planetary ball mill method (at $500 \mathrm{rpm}$ for $8 \mathrm{~h}$ ) to disperse GO in the matrix, and found that adding $0.1 \mathrm{wt} \%$ GO in $100 \%$ recycled concrete could be an alternative way to achieve sustainability in the construction industry.

As discussed above, ball milling provided an alternative method for dispersing CNMs in a cement matrix and showed great practical significance to fabricate CNMscement composites [93]. Note that, the ball-milling process can also result in cement powder fining, which increases the reactivity of cement particles [92, 116]. Thus, cautions should be taken when evaluating the true effects of CNMs on the performance of the obtained cement composites.

\section{Dispersion quality assessment}

Table 3 summarizes the current techniques are adopted to evaluate the dispersion quality of CNMs in water or cement matrix. As can be seen, much evidence reported the CNMs dispersion quality in water by techniques of UV-vis spectroscopy [82, 99], laser particle size analysis $[9,84]$, dynamic light scattering $[8,119]$, zeta potential [82, 109], optical microscope [82, 85], and SEM observation $[21,28,120,121]$. However, noted that the high dispersion quality of CNMs in water before mixing with cement is not necessarily resulting in high dispersion quality in the cement matrix.

Because cement is highly heterogeneous, including multiple phases and pores at multiple scales, the dispersion quality of CNMs in a cement matrix is very difficult to evaluate $[12,30,36,44,100]$. And the extremely low CNMs concentration (e.g., 0.01-0.1 wt\%) typically used further makes this task formidable. SEM equipped with energy dispersive spectrometer (EDS) has extensively been used to characterize the dispersion of CNMs in cement matrix [21, 28, 43, 122], although it is difficult to locate and even confirm that it is indeed CNMs due to the complexity of the hydration products. However, SEM cannot achieve quantitative characterization of CNMs dispersion in the cement matrix. The complete evaluation of CNMs dispersion and distribution in cement matrix is critically important for the design and optimization of the CNMs-cement interaction, and effectively promotes the effectiveness of CNMs. Recently, Cui et al. [99] found that the UV-Vis absorbance value of the GO suspension increased from 0.72-0.95 when ultrasonication energy increased from $15 \%$ to $60 \%$, indicating that higher ultrasonication energy resulted in a higher degree of GO dispersion. Additionally, they found that the ratio of Raman intensity of D band $\mathrm{G}$ band $\left(I_{D} / I_{G}\right.$ ratio) rose with increasing sonication energy. Therefore, the energy input of $30 \%$ was selected to obtain a balance between the GO dispersion [99]. This provides new possibilities

Table 3 Techniques are adopted to evaluate the dispersion quality of CNMs in suspension or cement matrix

\begin{tabular}{|c|c|c|c|}
\hline Methods & System & Description & Ref. \\
\hline UV-vis spectroscopy & \multirow[t]{4}{*}{ Suspension } & $\begin{array}{l}\text { Employing the Beer-Lambert Law to calculate the content of CNMs } \\
\text { according to the absorbance. }\end{array}$ & {$[4,82,99]$} \\
\hline Laser particle size & & \multirow[t]{2}{*}{ Smaller particle size indicates better dispersion } & {$[9,84]$} \\
\hline Dynamic light scattering & & & {$[8,119]$} \\
\hline Zeta potential & & Higher zeta potential value (absolute value) means better dispersion & {$[82,109]$} \\
\hline Optical microscope & \multirow{5}{*}{$\begin{array}{l}\text { Suspension/ } \\
\text { cement matrix }\end{array}$} & \multirow[t]{5}{*}{ Assessment of dispersion based on directly observed dimensions } & {$[82,85]$} \\
\hline SEM & & & {$[21,28,120,121]$} \\
\hline Transmission electron microscope & & & {$[22,32,87]$} \\
\hline X-ray photoelectron spectroscopy & & & {$[22,24,86,105,107,119]$} \\
\hline Raman spectrum & & & {$[86,120]$} \\
\hline
\end{tabular}


for a more refined characterization of CNMs dispersion in the cement matrix. However, such analysis is severely limited by the resolution of the laser point. Again, hydration products including ettringite (AFt), monosulfate $(\mathrm{AFm})$, and calcium hydroxide $(\mathrm{CH})$, all have their own shape factor (geometrically, AFt has nano-needle shape, while AFm and $\mathrm{CH}$ have nano-plate shape) [123, 124], which make it very difficult to distinguish them from the added CNMs. For instance, Meng et al. [125] used SEM to locate the distribution of graphene nanoplates, which as matter of fact, could also be AFm. Therefore, the employment of elemental mapping or other complementary techniques is necessary to confirm that the focused materials under SEM are indeed CNMs.

\section{Influence of CNMs on the performance of cement composites}

\section{Properties of fresh cement composites}

In this review work, the main properties of interest of fresh cement mixture including hydration kinetics and rheology properties, both of which will affect the subsequent mechanical and durability properties of hardened cement composites.

Despite the substantial research effort devoted to fulfilling the nucleation effect potential of the CNTs, previous reports of $\mathrm{CNTs}$ accelerate cement hydration are somewhat contradictory $[22,24,27,38]$, with some studies demonstrating an obvious acceleration effect [20,24] and others no effects or even retardation [27, 38], as illustrated in Fig. 6. For instance, an investigation was conducted by Sobolkina et al. [38], who indicated that the addition of either $0.25 \mathrm{wt} \% \mathrm{HNO}_{3}$-oxidized CNTs hardly affects $\mathrm{C}_{3} \mathrm{~S}$ hydration, and they argued that the insignificant effect was mainly due to the limited adsorption sites present on CNTs surface (Fig. 6a). It was hypothesized that some functional groups on the CNTs surface or other CNMs may stimulate cement hydration as the generation of additional calcium silicate hydrate (C-S-H) [38]. Tafesse et al. [27] reported that pure CNTs are not capable of activating or delaying cement hydration, based on the results of nonevaporated water (Fig. 6b), rather, they only provide nano-filler effect in cement composites.

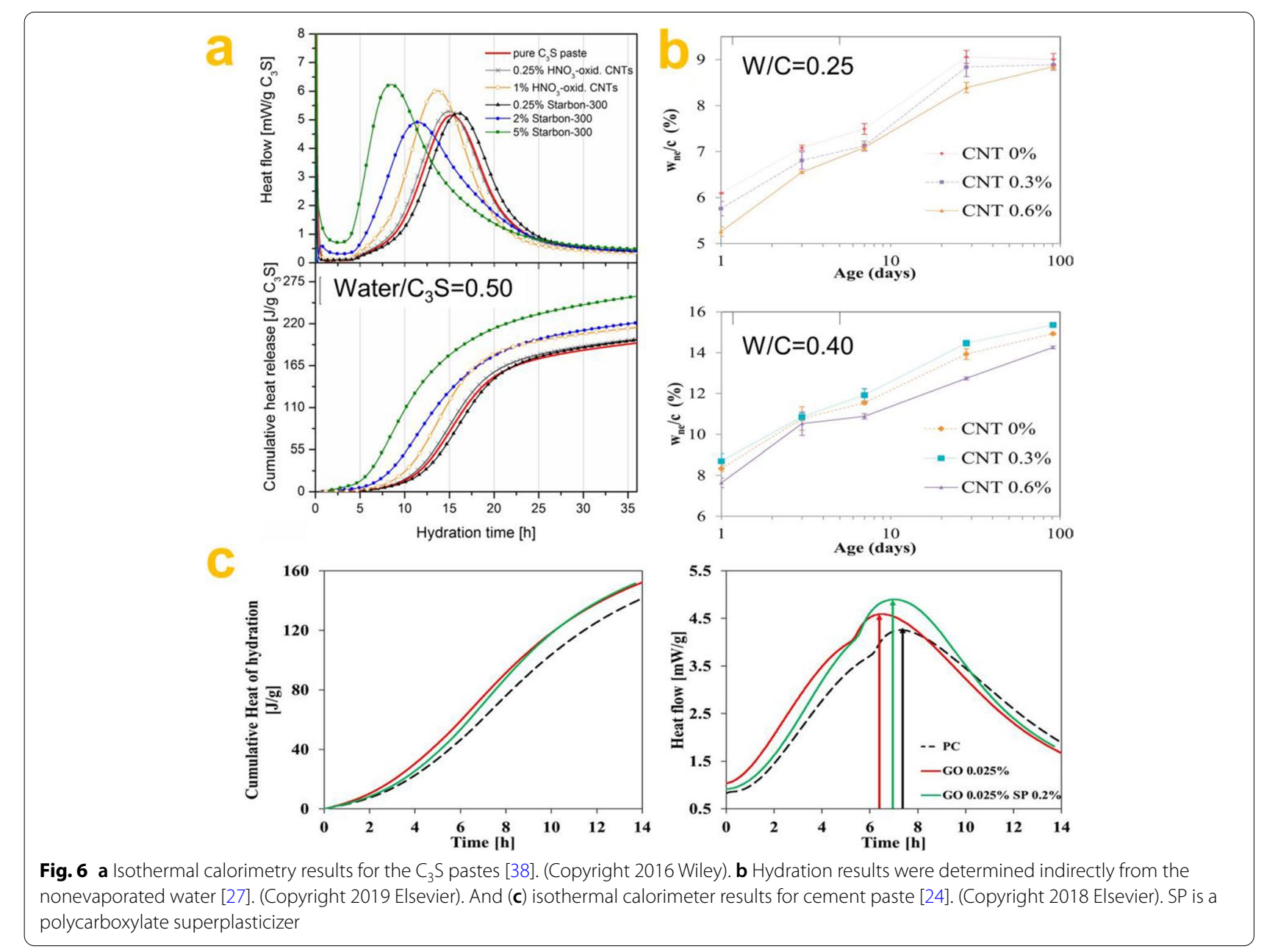


In contrast, Jung et al. [28] reported that the surface of the dispersed CNTs can contribute to precipitate cement hydrates. These inconsistent findings may be attributed to the dispersion quality and surface chemical affinity of CNTs. Note that the high surface area of CNTs cannot guarantee seeding effect, as reported by many groups $[27,38,126]$. It has been generally accepted that GO can accelerate cement hydration because of the rich oxygencontaining functional groups on its surface $[20,22,100]$. A recent study found the incorporation of $0.025 \mathrm{wt} \% \mathrm{GO}$ resulted in an earlier heat flow peak [24], as illustrated in Fig. 6c. A similar accelerating effect of GO on cement hydration was found in other studies [79, 127], in which the introduction of $0.025-0.10 \mathrm{wt} \%$ GO can significantly increase the heat flow of cement composites. Unfortunately, direct evidence for the seed effects of CNMs is still missing, which will be elaborated in the following.

Generally, adding CNMs to the cement matrix can lead to an improvement of viscosity (decreased workability), since the super-high SSA of nanoparticles requires more water for surface wetting $[5,31,36,44,100]$. The low viscosities of the fresh mixtures have a negative influence on the mixing and casting process and then affect the final mechanical and durability properties [5, 9]. According to the rheological parameters of paste obtained from the Bingham curve [128], the plastic viscosity $(\eta)$ of the cement mixture $(\mathrm{w} / \mathrm{c}=0.36)$ incorporating $0.03 \mathrm{wt} \% \mathrm{GO}$ (by weight of cement) was approximately $40 \%$ higher than that of the plain cement. Similarly, the admixing 0.3 $w t \%$ CNFs resulted in increased plastic viscosity of paste $(\mathrm{w} / \mathrm{c}=0.20)$ by approximately $35 \%[29]$.

Surfactants may be an ideal candidate to overcome this issue because of their steric hindrance and electrostatic repulsion $[29,44,97,107]$, which prevent the agglomeration of cement grains. As provided in Fig. 7, Li et al. [135] found that the introduction of SP significantly decreased the yield stress $(\sim 80 \%)$ and minimum viscosity $(\sim 70 \%)$ of cement pastes $(\mathrm{w} / \mathrm{c}=0.24)$ in the presence of graphene (at a dosage of $0.75 \mathrm{wt} \%$ ). However, in the presence of SP, especially the content over $0.75 \mathrm{wt} \%$, the admixing graphene can hardly influence the yield stress and minimum viscosity of cement pastes. Note that, the admixed CNMs may affect the compatibility between cement materials and surfactants thus affect the rheological properties of cement mixture $[29,136]$. In addition, a few studies reported that CNMs can lubricate solid particles in cement composites, which improved the flowability of the mixture [22, 29, 125]. Such knowledge gaps constrain the wider acceptance of CNMs in developing cementitious composites and drive the need for further research to advance the understanding.

\section{Properties of hardened cement composites properties Mechanical strengths}

Mechanical properties of cementitious composites are generally regarded as the most important performance in practical applications [12, 30, 31, 36, 44, 101]. During the past decades, it had been generally accepted that admixing a small dosage of CNMs to cement can result in remarkable improvement in the mechanical strengths (e.g., compressive, flexural, and tensile strength) [20, 28, $32,114,128,137]$.

Table 4 illustrates the experimental findings collected from the published reports related to the enhancement of $\mathrm{CNMs}$ to the mechanical strengths. As can be seen, GO (generally $0.01-0.10 \mathrm{wt} \%$, by weight of cement) is typically
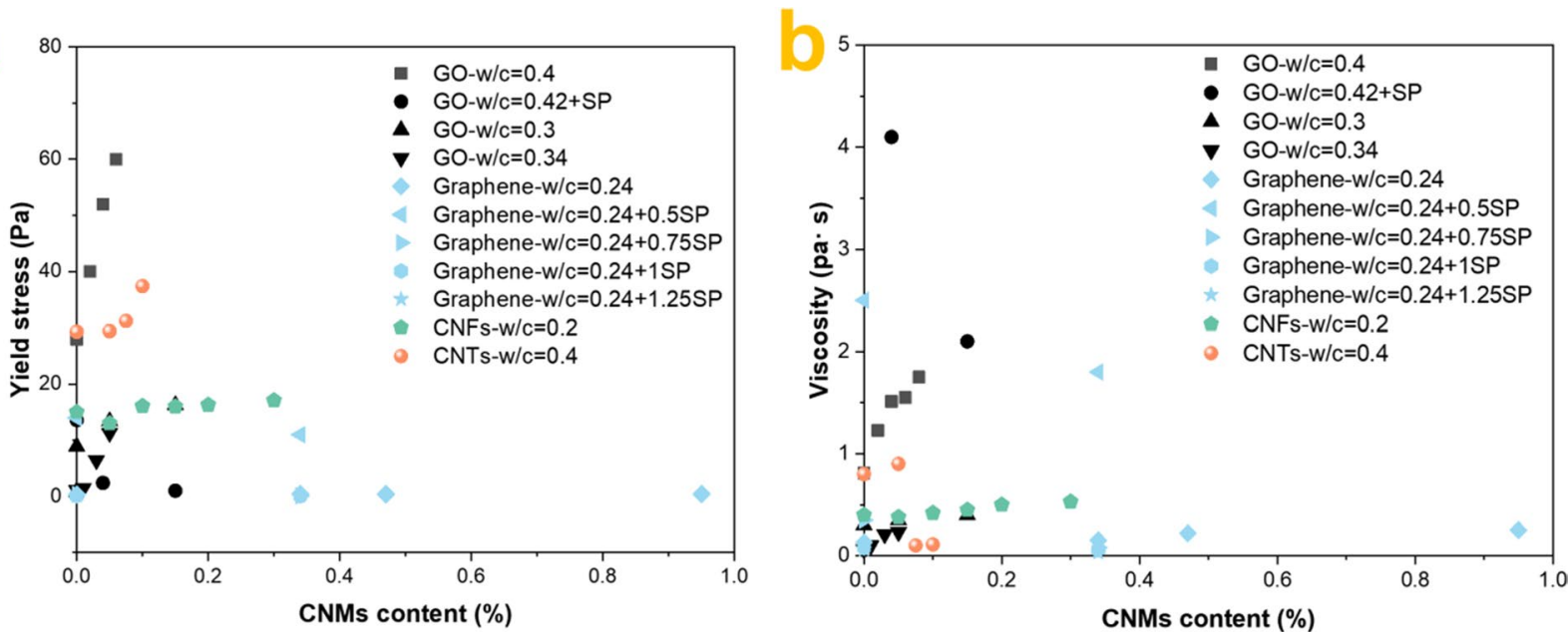

Fig. 7 Influence of CNMs on the rheology properties of fresh mixtures: a yield stress and $\mathbf{b}$ viscosity [22, 29, 97, 128-134]. SP is standing for polycarboxylate superplasticizer 
Table 4 Improvement of CNMs to mechanical properties of cement-based materials cured at 28 days

\begin{tabular}{|c|c|c|c|c|c|c|}
\hline \multirow[t]{2}{*}{ Matrix } & \multirow{2}{*}{$\begin{array}{l}\text { CNMs types } \\
\text { (by weight of cement) }\end{array}$} & \multirow[t]{2}{*}{$w / c$} & \multicolumn{3}{|c|}{ Increment in mechanical strengths } & \multirow[t]{2}{*}{ Ref. } \\
\hline & & & Compressive & Flexural & Tensile & \\
\hline Paste & Graphene (0.05 wt\%) & 0.35 & $3-8 \%$ & $15-24 \%$ & - & [138] \\
\hline Paste & Graphene (0.025 wt\%) & 0.40 & $14.9 \%$ & $23.6 \%$ & 15.2 & [139] \\
\hline Paste & Graphene (2 wt\%) & 0.38 & $-33.3 \%$ & & & [140] \\
\hline Paste & $\mathrm{GO}(0.05 \mathrm{wt} \%)$ & 0.35 & $29.0 \%$ & - & - & {$[20]$} \\
\hline Paste & $\mathrm{GO}(0.01 \mathrm{wt})$ & 0.30 & $10.0 \%$ & $15.6 \%$ & - & [79] \\
\hline Paste & $\mathrm{GO}(0.03 \mathrm{wt})$ & 0.30 & $20.1 \%$ & $27.3 \%$ & - & \\
\hline Paste & $\mathrm{GO}(0.05 \mathrm{wt})$ & 0.30 & $27.5 \%$ & $30.7 \%$ & - & \\
\hline Paste & CNFs (0.1 wt\%) & 0.485 & - & $20 \%$ & - & [34] \\
\hline Paste & CNTs (0.15 wt\%) & 0.40 & $14.3 \%$ & $3 \%$ & - & [141] \\
\hline Mortar & GO (0.022 wt\%) & 0.42 & $34.10 \%$ & $30.37 \%$ & $33.0 \%$ & [88] \\
\hline Mortar & GO (0.1 wt\%) & 0.48 & $27.7 \%$ & - & - & [142] \\
\hline Mortar & Graphene (0.05 wt\%) & N.A. & $8.3 \%$ & $15.6 \%$ & & [143] \\
\hline Mortar & $\mathrm{GO}(0.15$ wt\%) & 0.35 & $13.7 \%$ & $14.5 \%$ & & [94] \\
\hline Mortar & GO (0.01 wt\%) & 0.37 & $13.4 \%$ & $51.7 \%$ & $47.0 \%$ & {$[80]$} \\
\hline Mortar & GO (0.03 wt\%) & 0.37 & $38.9 \%$ & $60.7 \%$ & $78.6 \%$ & \\
\hline Mortar & GO (0.05 wt \%) & 0.37 & $47.9 \%$ & $30.2 \%$ & $35.8 \%$ & \\
\hline Mortar & CNTs (0.3 wt\%) & 0.40 & $-2.7 \%$ & - & - & [43] \\
\hline Mortar & CNTs (0.5 wt\%) & 0.60 & $-1.8 \%$ & - & - & \\
\hline Mortar & CNFs (0.1 wt\%) & 0.485 & 6.15 & - & - & [34] \\
\hline Concrete & CNFs (0.30 wt\%) & 0.20 & $60.0 \%$ & $10.1 \%$ & $55.0 \%$ & [29] \\
\hline Concrete & CNTs (0.002 wt $\%)$ & 0.23 & $-1.1 \%$ & - & - & {$[28]$} \\
\hline Concrete & CNTs (0.005 wt $\%)$ & 0.23 & $5.5 \%$ & - & - & \\
\hline Concrete & CNTs (0.008 wt\%) & 0.23 & $-0.8 \%$ & - & - & \\
\hline Concrete & CNTs (0.01wt\%) & 0.23 & $-4.9 \%$ & - & - & \\
\hline Concrete & CNFs (0.1 wt\%) & 0.51 & $8.13 \%$ & - & - & {$[34]$} \\
\hline Concrete & CNFs (0.10 wt\%) & 0.51 & $6.16 \%$ & - & - & [144] \\
\hline Concrete & Graphene (0.30 wt\%) & 0.20 & $40 \%$ & $59 \%$ & - & [125] \\
\hline Concrete & Graphene (0.10 wt\%) & 0.16 & 62.25 & 9.25 & - & {$[145]$} \\
\hline
\end{tabular}

used to manufacture cement paste and cement mortar, while CNFs and CNTs are generally used to fabricate cement concrete, especially used to prepare ultra-highperformance concrete. For improving the compressive strength of cement-based materials, the addition of GO is more effective than other CNMs, while CNTs and CNFs seem more effective for improving the flexural and tensile strengths of cement-based materials.

As illustrated in Fig. 8, the reinforcement mechanisms proposed by the current literature include i) acting as a nucleation site to promote cement hydration [20, 22, 24]. For instance, Sobolkina et al. [38] indicated that the CNMs with high SSA and rich in oxygen-containing functional groups on their surfaces have a nucleation effect on early $\mathrm{C}_{3} \mathrm{~S}$ hydration, as illustrated in Fig. 8a. Also, Birenboim et al. [22] reported that admixing a low concentration of GO $(<0.05 \mathrm{wt} \%)$ can increase the compressive strength of paste by $40 \%$, mainly due to the nanosize of GO act as a nucleation site. Interestingly, a large number of flower-like hydration crystals were grown on GO sheets (Fig. 8b), this phenomenon is possibly explained by the template effect of $\mathrm{GO}$, inducing hydrates growth in a specific space $[79,146]$. Notably, the nucleation effect is a prerequisite for the template effect and this phenomenon merely occurs in a cement matrix incorporating GO sheets, which has been observed by many reports $[39,46,79,80]$. ii) The nano-filler effect reduces the porosity and refines the microstructure [5, 88]. A recent study was carried out by Konstantopoulos et al. [147], who showed that introducing $0.5 \mathrm{wt} \%$ CNTs resulted in higher density hydrated phases and lower total porosity, this phenomenon was explained by nanoindentation as enhanced C-S-H connectivity in the porous network. Besides, Birenboim et al. [22] found that a dense microstructure was achieved with the addition of $0.03 \mathrm{wt} \% \mathrm{GO}$, mainly due to the admixed GO nanosheets that can act as a nanofiller that refined the microstructure (Fig. 8c). However, considering the small number of 


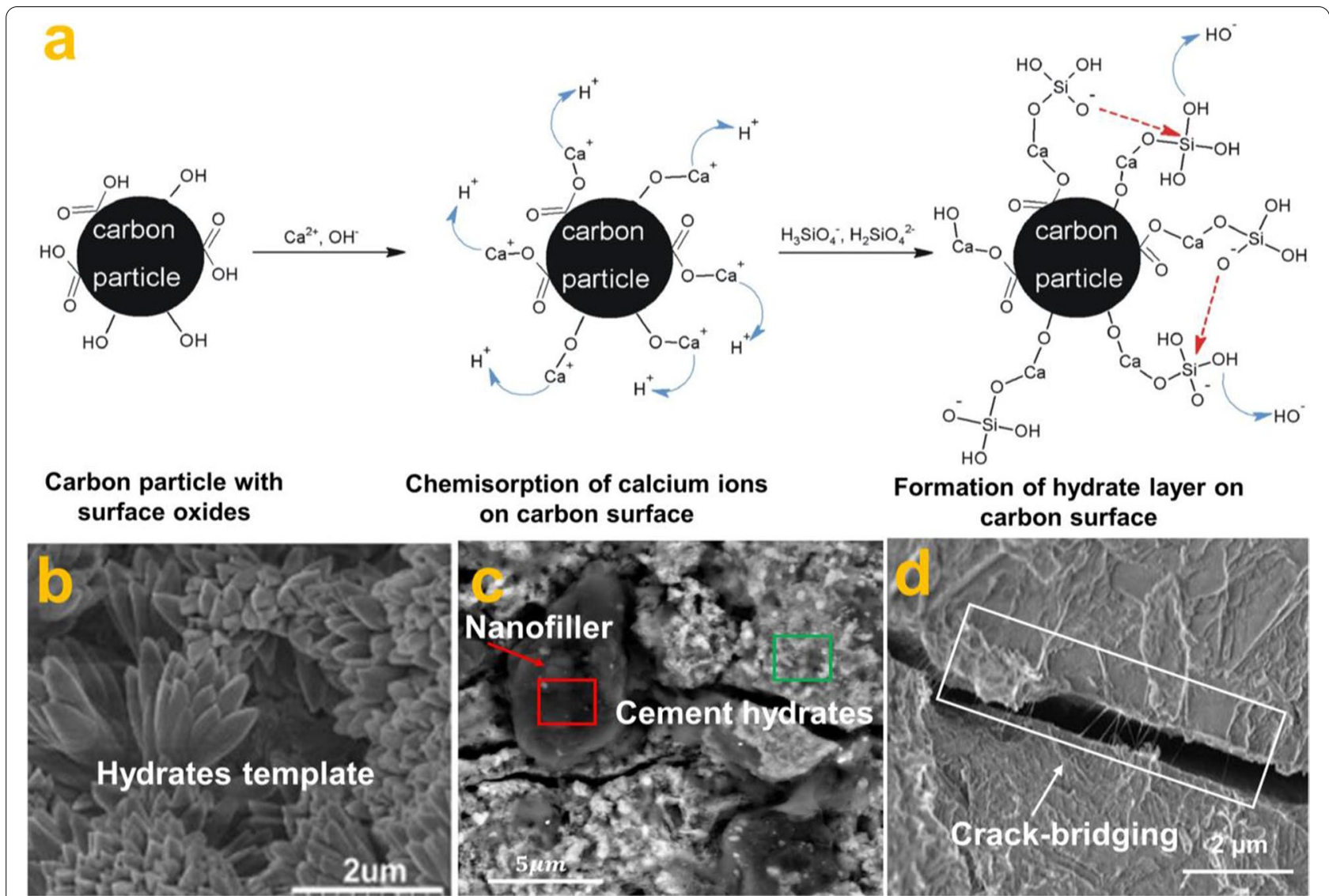

Fig. 8 Reinforcement mechanisms of CNMs in cement matrix: a nucleation effect [38]. (Copyright 2016 Wiley). b template effect [79]. (Copyright 2014 Elsevier). c nano-filler effect [22]. (Copyright 2019 Elsevier). And (d) crack-bridging effect [30]. (Copyright 2019 Elsevier)

CNMs that are utilized, typically less than $0.1 \mathrm{wt} \%$, purely physical filler effects are probably negligible. And iii) the bridging effect to inhibit microcracks propagation $[8,27-$ 29]. Silvestro et al. [91] indicated that the incorporation of $0.1 \mathrm{wt} \%$ CNTs increased the 28-d compressive and tensile strengths of a cement paste by up to $30 \%$ and $50 \%$, respectively. The microcracks were eliminated with the addition of CNTs and CNFs [148, 149], and the admixing CNMs plays a dominant role in enhancing the flexural strength and tensile strength of cement composites because of their larger aspect ratio (Fig. 8d), as discussed in section 2 .

Recent work was conducted by $\mathrm{Xu}$ and Shi et al. [20], who found that the admixing $0.02 \mathrm{wt} \%$ GO promoted cement hydration to generate Si-rich phases (tobermorite-like hydrate) and Ca-rich hydrates (jennite-like structure), instead of ordinary C-S-H gel. This seems to provide a new possibility to explain the possible mechanisms of GO-reinforced cement composites. Note that the reported experimental evidence mainly comes from SEM images of fractures cement composites samples, where CNMs are exposed and hydration products can be observed to be attached on CNMs. Note that, this phenomenon can be also induced by the growth of hydration products far away from CNMs, and CNMs are merely passively embedded inside. Recently, we have employed CNTs sponges, with unique nano-pores microstructure, as a platform to in-situ separate pore solution from cement grains [71]. The experiments directly prove that CNT with and without strong acid treatment are all inert for cement hydration, and there is no seed effect.

\section{Durability}

Durability is critical to guarantee the reliability and stability of cement composites [5, 12, 31, 36, 37, 101]. Typically, their durability is evaluated in terms of transport properties and chemical resistance [30,37]. It is an issue attracting wide interest in the application of cementitious composites as it relates to the safety, service life, and maintenance costs [30, 150-153]. Currently, the durability of CNMs reinforced cement composites has not been sufficiently studied, compared to the comprehensive studies concerning their mechanical properties. This section summarized the findings brought out by CNMs in 
the durability of cement composites in recent literature, including transport property and chemical degradation.

Transport properties of cement composite reflect its resistance to the ingress of aggressive agents (e.g., water and ions, etc.) to pass through inside [12, 30, 36, 150, 151], which can be improved by introducing well-dispersed CNMs [122, 152]. For instance, an investigation was carried out by Qureshi et al. [153], who reported that the maximum water vapor adsorption at $98 \%$ relative humidity increased up to $2 \%$ in the $0.06 \%$ GO-cement composites, suggesting additional C-S-H gel was formed in the cement composites, which can induce a denser microstructure (see Fig. 9). A similar result has been observed by others $[53,112]$, who found that the water absorption and gas permeability of a cement composite could be reduced by $10-20 \%$ with the addition of GO. Similar to the role of GO in the cement matrix, CNTs or CNFs possess the nanofiller effect and bridging effect to improve the microstructure of cementitious materials [28-30, 122].
Chemical degradation of cement-based materials generally includes sulfate attack, carbonation, and acid attack $[12,30,36,37]$. As discussed above, the addition of CNMs also showed great potential to improve the chemical resistance for cement composites. For example, the introduction of $0.03 \mathrm{wt} \%$ GO reduced the carbonation depth due to the movement of $\mathrm{CO}_{2}$ molecules into the cement matrix was restricted by GO, that is, the reduction of carbonation depth of GO-reinforced cement composites is related to the reduced porosity $[53,154]$. Also, Long et al. [53] found that the introduction of $0.2 \mathrm{wt} \%$ GO could reduce the carbonation depth by approximately $40 \%$ after 28 days, mainly due to the reduced porosity and refined pore structure, as presented in Fig. 10a. According to Mohammed et al. [155], who reported that a considerable decrease (from $11 \mathrm{~mm}$ to $2 \mathrm{~mm}$ ) of carbonation depth in a cement specimen incorporating $0.06 \mathrm{wt} \% \mathrm{GO}$ after 15 months, this result has attributed the benefit to the increased air content and the decreased mesopore volume (see Fig. 10b and c). Similarly, a recent study was
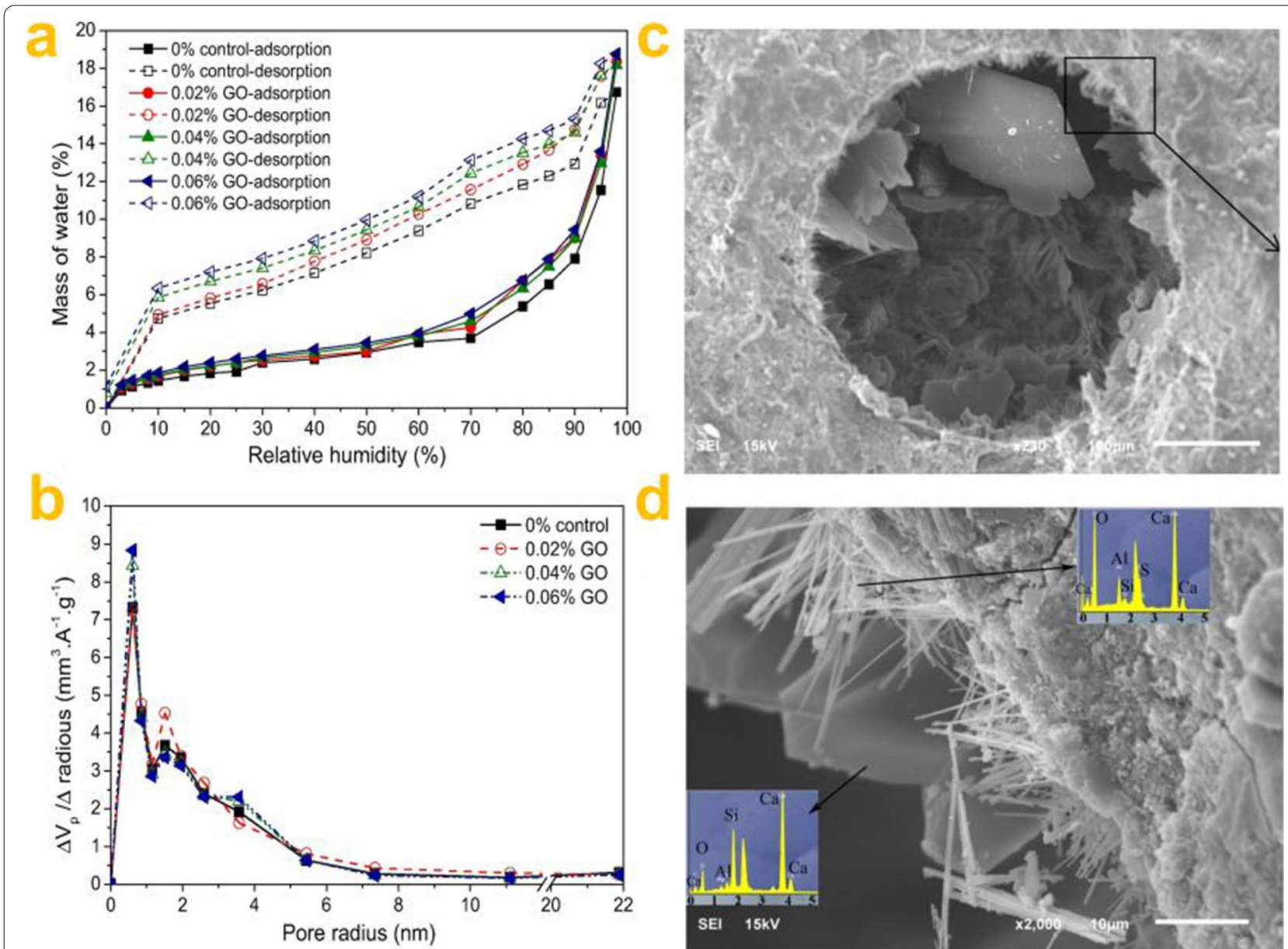

Fig. 9 Properties of cement composites with the addition of GO: a mass loss $\mathbf{b}$ pore size distribution c SEM images of mixture with 0.06 wt\% GO, and $\mathbf{d}$ magnification of black rectangle indicating the surface growth nature of flake structures and AFt [153]. (Copyright 2019 Elsevier) 


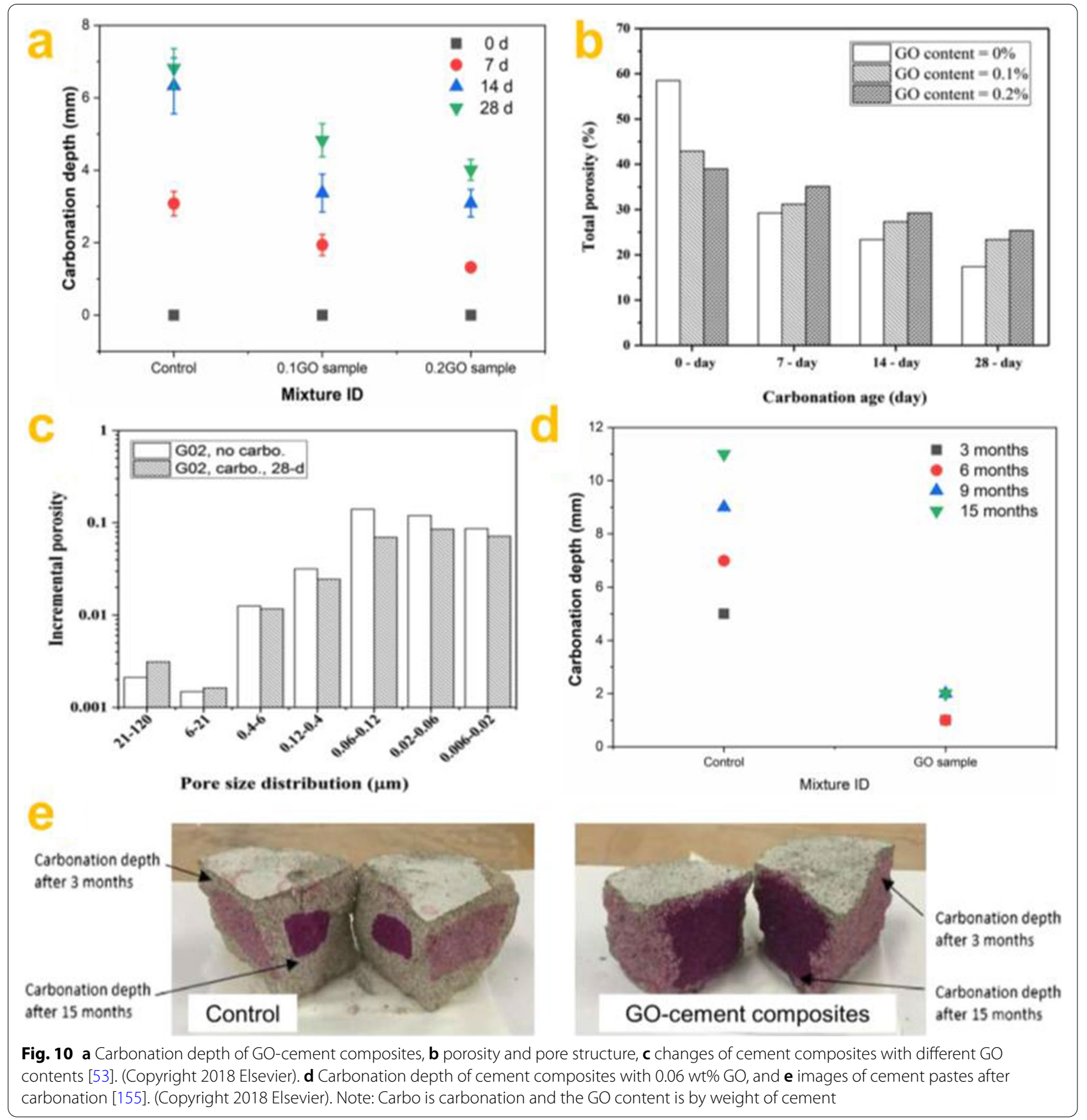

carried out by Li et al. [47], who reported that the weight loss of a paste specimen incorporating CNTs decreased by $13.3 \%$. A similar beneficial role of CNTs or CNFs on the chemical resistance of cement composites was also found in other studies and attributed this benefit to the refinement microstructure [21, 22, 27-29].

Overall, the addition of CNMs has demonstrated a promising durability performance for cement materials. Compared with CNTs or CNFs, GO has a much higher
SSA and abundant hydrophilic functional groups, enabling it to perform better in improving the durability of cement-based materials. Currently, although the consensus is that the durability of cement-based materials strongly relies on both strength and microstructure, the fundamental mechanisms underlying the durability damage of CNMs-reinforced cement-based materials are not fully unraveled. To this end, more in-depth studies should be explored in the future to verify this hypothesis. 


\section{Conclusions and remaining challenges}

Over the past decade, the addition of a small dosage of CNMs has demonstrated great potential to improve the mechanical and durability properties of cement composites. We summarized the relevant publications in the last decade (from 2011 to 2021), and the main findings and remaining challenges identified from the literature review can be drawn as follows:

1) The dispersion quality and distribution of CNMs in the cement matrix are the keys to understand their roles in the cement matrix. Although previous studies on the admixed CNMs have achieved some satisfactory achievements in terms of reinforcement efficiency [20, 22, 29, 88, 104, 156], the effective dispersion of CNMs in the cement matrix is still a top challenge. Also, semi-quantitative or quantitative evaluation of the dispersion and distribution of CNMs in cement composites faces great challenges, which constrains their feasibility to be widely utilized in the construction industry.

2) It has been generally accepted that the addition of $\mathrm{GO}$ can accelerate cement hydration, where admixed GO mainly demonstrated the nanofiller and hydration template roles. In addition, the negatively charged GO could consume $\mathrm{Ca}$ ions, thereby affecting the degree of polymerization of the cement hydrates. However, direct evidence is still very limited, more detailed investigations need to proceed to investigate the influence of admixed GO on the formation of cement hydrates. Especially the cement hydration lasts for a long time and a variety of hydrates are produced at different times, and how (when) the admixed GO affects cement hydration is still needs to be further in-depth studied.

3) Pure CNTs or CNFs are generally not capable of activating or delaying the hydration products, rather, they offer a nanofiller and cracking-bridging capability in cement composites. Interestingly, it has been found that the CNTs rich in oxygen-containing functional groups demonstrated the potential to promote cement hydration. Overall, the admixed CNTs that accelerated the cement hydration have not yet been unanimously agreed upon. Although previous studies claimed that the nucleation effect of the admixed CNMs in the cement hydration, direct evidence is still missing. Note that recently, we have utilized CNTs sponge as a platform to investigate the true effects of CNT on the growth of cement hydration products, and the results indicate that CNT with and without acid treatment have no seed effects.

4) For the fresh mixtures, the introduction of CNMs results in higher viscosity, that is, the admixed CNMs harm the setting time and workability of the mixtures, which is not conducive to the later transportation, casting, and compaction process. Fortunately, this may be compensated by employing some SCMs, such as fly ash.

5) At present, the research of CNMs-engineered cement composites is a booming field and there are many handicaps to be overcome. The admixing an extremely low concentration of CNMs has a positive influence on the mechanical strengths of cementbased materials, on the premise of effective dispersion. More attention should be paid to investigate the effects of various CNMs on the formation of multiple cement hydrates. Additionally, CNMs demonstrate great potential to develop smart cement composites in the future.
Abbreviations

SCMs: Supplementary cementitious materials; CNMs: Carbon-based nanomaterials; CNTs: Carbon nanotubes; CNFs: Carbon nanofibers; G: Graphene; GO: Graphene oxide; 1D: One-dimensional; 2D: Two-dimensional; ITZ: Interfacial transitional zone; OEGO: Electrochemically gathered graphite oxide; EGO: Electrochemically gathered graphene oxide; GIC: Graphite intercalation compound; SP: Polycarboxylate superplasticizer; SSA: Specific surface area; AFt: Ettringite; AFm: Monosulfate; $\mathrm{CH}$ : Calcium hydroxide; C-S-H: Calcium-SilicateHydrate; SEM: Scanning electron microscopy; TEM:Transmission electron microscopy; XRD: X-ray diffraction; EDS: Energy dispersive spectrometer.

\section{Acknowledgments}

The authors would like to thank Mr. Mingchao Ren for his assistance in data collection.

\section{Authors' contributions}

Dong Lu: Data processing, Writing-Original draft preparation, and WritingReviewing and Editing. Jing Zhong: Conceptualization, Methodology, Supervision, Writing- Reviewing and Editing. The authors read and approved the final manuscript.

\section{Funding}

This work was supported by the National Natural Science Foundation of China [52073073]. The findings and conclusions reported in this article only reflect the view of the authors and do not reflect the view of the above entities.

Availability of data and materials

All data generated or analyzed during this study are included in this article.

\section{Declarations}

\section{Competing interests}

The authors declare that they have no known competing financial interests or personal relationships that could have appeared to influence the work reported in this paper.

\section{Author details}

${ }^{1}$ School of Civil Engineering, Harbin Institute of Technology, 73 Huanghe Road, Harbin, Heilongjiang 150090, P. R. China. ${ }^{2}$ Key Lab of Structures Dynamic Behavior and Control of the Ministry of Education (Harbin Institute of Technology), Harbin 150090, P. R. China. 
Received: 11 September 2021 Accepted: 21 October 2021

Published online: 19 January 2022

\section{References}

1. Monteiro PJM, Miller SA, Horvath A (2017) Towards sustainable concrete. Nat Mater 16(7):698-699. https://doi.org/10.1038/nmat4930

2. Zhang C-Y, Han R, Yu B, Wei Y-M (2018) Accounting process-related $\mathrm{CO}_{2}$ emissions from global cement production under Shared Socioeconomic Pathways. J Clean Prod 184:451-465. https://doi.org/10.1016/j. jclepro.2018.02.284

3. Geng Y, Wang Z, Shen L, Zhao J (2019) Calculating of $\mathrm{CO}_{2}$ emission factors for Chinese cement production based on inorganic carbon and organic carbon. J Clean Prod 217:503-509. https://doi.org/10.1016/j. jclepro.2019.01.224

4. Paul SC, van Rooyen AS, van Zijl GPAG, Petrik LF (2018) Properties of cement-based composites using nanoparticles: A comprehensive review. Constr Build Mater 189:1019-1034. https://doi.org/10.1016/j. conbuildmat.2018.09.062

5. Singh NB, Kalra M, Saxena SK (2017) Nanoscience of Cement and Concrete. Materials Today: Proceedings 4(4):5478-5487. https://doi.org/10. 1016/j.matpr.2017.06.003

6. Wu Z, Khayat $\mathrm{KH}$, Shi C (2017) Effect of nano-SiO, particles and curing time on development of fiber-matrix bond properties and microstructure of ultra-high strength concrete. Cem Concr Res 95:247-256. https://doi.org/10.1016/j.cemconres.2017.02.031

7. Chen J, Akono A-T (2020) Influence of multi-walled carbon nanotubes on the hydration products of ordinary Portland cement paste. Cement and Concrete Res 137. https://doi.org/10.1016/j.cemconres.2020. 106197

8. Du Y, Yang J, Skariah Thomas B, Li L, Li H, Nazar S (2020) Hybrid graphene oxide/carbon nanotubes reinforced cement paste: An investigation on hybrid ratio. Construction Building Materials 261. https://doi. org/10.1016/j.conbuildmat.2020.119815

9. Li Z, Fei M-E, Huyan C, Shi X (2020) Nano-engineered, Fly Ash-Based Geopolymer Composites: An Overview, Resources, Conservation and Recycling. https://doi.org/10.1016/j.resconrec.2020.105334

10. Cao Z, Shen L, Zhao J, Liu L, Zhong S, Sun Y, Yang Y (2016) Toward a better practice for estimating the $\mathrm{CO}_{2}$ emission factors of cement production: An experience from China. J Clean Prod 139:527-539. https://doi. org/10.1016/j.jclepro.2016.08.070

11. Cloete S, Giuffrida A, Romano MC, Zaabout A (2020) Economic assessment of the swing adsorption reactor cluster for $\mathrm{CO} 2$ capture from cement production. J Cleaner Product, 275. https://doi.org/10.1016/j. jclepro.2020.123024

12. Xu G, Shi X (2018) Characteristics and applications of fly ash as a sustainable construction material: A state-of-the-art review. Resour Conserv Recycl 136:95-109. https://doi.org/10.1016/j.resconrec.2018. 04.010

13. Lu D, Tang Z, Zhang L, Zhou J, Gong Y, Tian Y, Zhong J (2020) Effects of Combined Usage of Supplementary Cementitious Materials on the Thermal Properties and Microstructure of High-Performance Concrete at High Temperatures. Materials (Basel) 13(8). https://doi.org/10.3390/ ma13081833

14. Lu D, Zhong J, Yan B, Gong J, He Z, Zhang G, Song C (2021) Effects of Curing Conditions on the Mechanical and Microstructural Properties of Ultra-High-Performance Concrete (UHPC) Incorporating Iron Tailing Powder. Materials (Basel) 14(1). https://doi.org/10.3390/ma14010215

15. Lu D, Wang Y, Leng Z, Zhong J (2021) Influence of ternary blended cementitious fillers in a cold mix asphalt mixture. J Clean Prod. https:// doi.org/10.1016/j.jclepro.2021.128421

16. Xu G, Zhong J, Shi X (2018) Influence of graphene oxide in a chemically activated fly ash. Fuel 226:644-657. https://doi.org/10.1016/j.fuel.2018. 04.033

17. Wang Z, Yu Q, Gauvin F, Feng P, Qianping R, Brouwers HJH (2020) Nanodispersed TiO2 hydrosol modified Portland cement paste: The underlying role of hydration on self-cleaning mechanisms. Cement Concrete Res 136. https://doi.org/10.1016/j.cemconres.2020.106156

18. Hou P, Shi J, Prabakar S, Cheng X, Wang K, Zhou X, Shah SP (2020) Effects of mixing sequences of nanosilica on the hydration and hardening properties of cement-based materials. Construction Building Materials, 263. https://doi.org/10.1016/j.conbuildmat.2020.120226

19. Konsta-Gdoutos MS, Metaxa ZS, Shah SP (2010) Highly dispersed carbon nanotube reinforced cement based materials. Cem Concr Res 40(7):1052-1059. https://doi.org/10.1016/j.cemconres.2010.02.015

20. Xu G, Du S, He J, Shi X (2019) The role of admixed graphene oxide in a cement hydration system. Carbon 148:141-150. https://doi.org/10. 1016/j.carbon.2019.03.072

21. J. Wang, J. Tao, L. Li, C. Zhou, Q. Zeng, Thinner fillers, coarser pores? A comparative study of the pore structure alterations of cement composites by graphene oxides and graphene nanoplatelets, Composites Part A: Applied Science and Manufacturing 130 (2020). https://doi.org/10. 1016/j.compositesa.2019.105750

22. Birenboim M, Nadiv R, Alatawna A, Buzaglo M, Schahar G, Lee J, Kim G, Peled A, Regev O (2019) Reinforcement and workability aspects of graphene-oxide-reinforced cement nanocomposites. Compos Part B 161:68-76. https://doi.org/10.1016/j.compositesb.2018.10.030

23. Chintalapudi K, Pannem RMR (2020) The effects of Graphene Oxide addition on hydration process, crystal shapes, and microstructural transformation of Ordinary Portland Cement. J Building Eng 32. https:// doi.org/10.1016/j.jobe.2020.101551

24. Ghazizadeh S, Duffour P, Skipper NT, Bai Y (2018) Understanding the behaviour of graphene oxide in Portland cement paste. Cem Concr Res 111:169-182. https://doi.org/10.1016/j.cemconres.2018.05.016

25. Chen J, Kou S-C, Poon C-S (2012) Hydration and properties of nano-TiO2 blended cement composites. Cem Concr Compos 34(5):642-649. https://doi.org/10.1016/j.cemconcomp.2012.02.009

26. Hou P, Cheng X, Qian J, Zhang R, Cao W, Shah SP (2015) Characteristics of surface-treatment of nano-SiO 2 on the transport properties of hardened cement pastes with different water-to-cement ratios. Cem Concr Compos 55:26-33. https://doi.org/10.1016/j.cemconcomp.2014.07.022

27. Tafesse M, Kim H-K (2019) The role of carbon nanotube on hydration kinetics and shrinkage of cement composite. Compos Part B 169:55-64. https://doi.org/10.1016/j.compositesb.2019.04.004

28. Jung M, Lee Y-s, Hong S-G, Moon J (2020) Carbon nanotubes (CNTs) in ultra-high performance concrete (UHPC): Dispersion, mechanical properties, and electromagnetic interference (EMI) shielding effectiveness (SE). Cem Concr Res 131. https://doi.org/10.1016/j.cemconres.2020. 106017

29. Meng W, Khayat KH (2018) Effect of graphite nanoplatelets and carbon nanofibers on rheology, hydration, shrinkage, mechanical properties, and microstructure of UHPC. Cem Concr Res 105:64-71. https://doi.org/ 10.1016/j.cemconres.2018.01.001

30. Shi T, Li Z, Guo J, Gong H, Gu C (2019) Research progress on CNTs/CNFsmodified cement-based composites - A review. Constr Build Mater 202:290-307. https://doi.org/10.1016/j.conbuildmat.2019.01.024

31. Alkhateb H, Al-Ostaz A, Cheng AHD, Li X (2013) Materials Genome for Graphene-Cement Nanocomposites. J Nanomechanics Micromechanics 3(3):67-77. https://doi.org/10.1061/(asce)nm.2153-5477.0000055

32. K. Chintalapudi, R.M. Rao Pannem, Strength properties of graphene oxide cement composites, Materials Today: Proceedings (2020). https:// doi.org/10.1016/j.matpr.2020.08.369

33. Du H, Gao HJ, Pang SD (2016) Improvement in concrete resistance against water and chloride ingress by adding graphene nanoplatelet. Cem Concr Res 83:114-123. https://doi.org/10.1016/j.cemconres.2016. 02.005

34. Gao Y, Zhu X, Corr DJ, Konsta-Gdoutos MS, Shah SP (2019) Characterization of the interfacial transition zone of CNF-Reinforced cementitious composites. Cem Concr Compos 99:130-139. https://doi.org/10.1016/j. cemconcomp.2019.03.002

35. Konsta-Gdoutos MS, Metaxa ZS, Shah SP (2010) Multi-scale mechanical and fracture characteristics and early-age strain capacity of high performance carbon nanotube/cement nanocomposites. Cem Concr Compos 32(2):110-115. https://doi.org/10.1016/j.cemconcomp.2009. 10.007

36. Lin Y, Du H (2020) Graphene reinforced cement composites: A review. Constr Build Mater 265. https://doi.org/10.1016/j.conbuildmat.2020. 120312

37. Zhao L, Guo X, Song L, Song Y, Dai G, Liu J (2020) An intensive review on the role of graphene oxide in cement-based materials. Constr Build Mater 241. https://doi.org/10.1016/j.conbuildmat.2019.117939 
38. Sobolkina A, Mechtcherine V, Bergold ST, Neubauer J, Bellmann C, Khavrus V, Oswald S, Leonhardt A, Reschetilowski W, Scherer G (2016) Effect of Carbon-Based Materials on the Early Hydration of Tricalcium Silicate. J Am Ceram Soc 99(6):2181-2196. https://doi.org/10.1111/jace. 14187

39. Li H, Du T, Xiao H, Zhang Q (2017) Crystallization of calcium silicate hydrates on the surface of nanomaterials. J Am Ceram Soc 100(7):32273238. https://doi.org/10.1111/jace.14842

40. Dong W, Guo Y, Sun Z, Tao Z, Li W (2021) Development of piezoresistive cement-based sensor using recycled waste glass cullets coated with carbon nanotubes. J Clean Prod 314:127968. https://doi.org/10.1016/j. jclepro.2021.127968

41. Azhari F, Banthia N (2012) Cement-based sensors with carbon fibers and carbon nanotubes for piezoresistive sensing. Cem Concr Compos 34(7):866-873. https://doi.org/10.1016/j.cemconcomp.2012.04.007

42. Dong W, Li W, Vessalas K, He X, Sun Z, Sheng D (2021) Piezoresistivity deterioration of smart graphene nanoplate/cement-based sensors subjected to sulphuric acid attack. Composites Commun 23 https://doi. org/10.1016/j.coco.2020.100563

43. LiW, Dong W, Shen L, Castel A, Shah SP (2020) Conductivity and piezoresistivity of nano-carbon black (NCB) enhanced functional cement-based sensors using polypropylene fibres. Mater Lett 270. https://doi.org/10.1016/j.matlet.2020.127736

44. Dong S, Li L, Ashour A, Dong X, Han B (2020) Self-assembled OD/2D nano carbon materials engineered smart and multifunctional cementbased composites. Constr Build Mater. https://doi.org/10.1016/j.conbu ildmat.2020.121632

45. Wang L, Aslani F (2019) A review on material design, performance, and practical application of electrically conductive cementitious composites. Constr Build Mater 229. https://doi.org/10.1016/j.conbuildmat. 2019.116892

46. Lv SH, Deng LJ, Yang WQ, Zhou QF, Cui YY (2016) Fabrication of polycarboxylate/graphene oxide nanosheet composites by copolymerization for reinforcing and toughening cement composites. Cem Concr Compos 66:1-9. https://doi.org/10.1016/j.cemconcomp.2015.11.007

47. Li GY, Wang PM, Zhao X (2007) Pressure-sensitive properties and microstructure of carbon nanotube reinforced cement composites. Cem Concr Compos 29(5):377-382. https://doi.org/10.1016/j.cemconcomp. 2006.12.011

48. Nadiv R, Shtein M, Refaeli M, Peled A, Regev O (2016) The critical role of nanotube shape in cement composites. Cem Concr Compos 71:166-174. https://doi.org/10.1016/j.cemconcomp.2016.05.012

49. Rao R, Sindu BS, Sasmal S (2020) Synthesis, design and piezo-resistive characteristics of cementitious smart nanocomposites with different types of functionalized MWCNTs under long cyclic loading. Cem Concr Compos 108. https://doi.org/10.1016/j.cemconcomp.2020.103517

50. Chen Z, Lim JLG, Yang E-H (2016) Ultra high performance cementbased composites incorporating low dosage of plasma synthesized carbon nanotubes. Mater Des 108:479-487. https://doi.org/10.1016/j. matdes.2016.07.016

51. Li W, Li X, Chen SJ, Long G, Liu YM, Duan WH (2017) Effects of Nanoalumina and Graphene Oxide on Early-Age Hydration and Mechanical Properties of Cement Paste. J Mater Civ Eng 29(9). https://doi.org/10. 1061/(asce)mt.1943-5533.0001926

52. Liu F, Zhang $X$, Cheng J, Tu J, Kong F, Huang W, Chen C (2003) Preparation of short carbon nanotubes by mechanical ball milling and their hydrogen adsorption behavior. Carbon 41(13):2527-2532. https://doi. org/10.1016/s0008-6223(03)00302-6

53. Long W-J, Gu Y-c, Xing F, Khayat KH (2018) Microstructure development and mechanism of hardened cement paste incorporating graphene oxide during carbonation. Cem Concr Compos 94:72-84. https://doi. org/10.1016/j.cemconcomp.2018.08.016

54. Wu Q, Ji Z, Xin L, Li D, Zhang L, Liu C, Yang T, Wen Z, Wang H, Xin B, Xue $\mathrm{H}$, Chen F, Xu Z, Cui H, He M (2019) Iron silicide-catalyzed growth of single-walled carbon nanotubes with a narrow diameter distribution. Carbon 149:139-143. https://doi.org/10.1016/j.carbon.2019.04.059

55. Lijima S (1991) Helical microtubules of graphitic carbon. Nature 354(17):56-58

56. Vigolo B, Penicaud A, Coulon C, Sauder C, Pailler R, Journet C, Bernier $P$, Poulin P (2000) Macroscopic fibers and ribbons of oriented carbon nanotubes. Science 290(5495):1331-1334. https://doi.org/10.1126/ science.290.5495.1331

57. Shin MK, Oh J, Lima M, Kozlov ME, Kim SJ, Baughman RH (2010) Elastomeric conductive composites based on carbon nanotube forests. Adv Mater 22(24):2663-2667. https://doi.org/10.1002/adma.200904270

58. Barnard AW, Zhang M, Wiederhecker GS, Lipson M, McEuen PL (2019) Real-time vibrations of a carbon nanotube. Nature 566(7742):89-93. https://doi.org/10.1038/s41586-018-0861-0

59. Song C, Hong G, Choi S (2020) Effect of dispersibility of carbon nanotubes by silica fume on material properties of cement mortars: Hydration, pore structure, mechanical properties, self-desiccation, and autogenous shrinkage. Constr Build Mater 265. https://doi.org/10. 1016/j.conbuildmat.2020.120318

60. Alafogianni P, Dassios K, Tsakiroglou CD, Matikas TE, Barkoula NM (2019) Effect of CNT addition and dispersive agents on the transport properties and microstructure of cement mortars. Constr Build Mater 197:251-261. https://doi.org/10.1016/j.conbuildmat.2018.11.169

61. De Jong KP, Geus JW (2007) Carbon Nanofibers: Catalytic Synthesis and Applications. Catal Rev 42(4):481-510. https://doi.org/10.1081/cr-10010 1954

62. Sun S, Yu X, Han B, Ou J (2013) In situ growth of carbon nanotubes/ carbon nanofibers on cement/mineral admixture particles: A review. Constr Build Mater 49:835-840. https://doi.org/10.1016/j.conbuildmat. 2013.09.011

63. Zhong J, Sun W, Wei Q, Qian X, Cheng HM, Ren W (2018) Efficient and scalable synthesis of highly aligned and compact two-dimensional nanosheet films with record performances. Nat Commun 9(1):3484. https://doi.org/10.1038/s41467-018-05723-2

64. Zhu Y, Murali S, Cai W, Li X, Suk JW, Potts JR, Ruoff RS (2010) Graphene and graphene oxide: synthesis, properties, and applications. Adv Mater 22(35):3906-3924. https://doi.org/10.1002/adma.201001068

65. Zhong J, Meng J, Gui X, Hu T, Xie N, Lu X, Yang Z, Koratkar N (2014) Nanocarbon aerogel complexes inspired by the leaf structure. Carbon 77:637-644. https://doi.org/10.1016/j.carbon.2014.05.068

66. Wang Y, Lu D, Wang F, Zhang D, Zhong J, Liang B, Gui X, Sun L (2020) A new strategy to prepare carbon nanotube thin film by the combination of top-down and bottom-up approaches. Carbon 161:563-569. https:// doi.org/10.1016/j.carbon.2020.01.090

67. Xu S, Dall'Agnese Y, Li J, Gogotsi Y, Han W (2018) Thermally Reduced Graphene/MXene Film for Enhanced Li-ion Storage. Chemistry 24(69):18556-18563. https://doi.org/10.1002/chem.201805162

68. Cao J, He P, Mohammed MA, Zhao X, Young RJ, Derby B, Kinloch IA, Dryfe RAW (2017) Two-Step Electrochemical Intercalation and Oxidation of Graphite for the Mass Production of Graphene Oxide. J Am Chem Soc 139(48):17446-17456. https://doi.org/10.1021/jacs.7b08515

69. Li Z, Young RJ, Kinloch IA (2013) Interfacial stress transfer in graphene oxide nanocomposites. ACS Appl Mater Interfaces 5(2):456-463. https://doi.org/10.1021/am302581e

70. Zhan M, Pan G, Zhou F, Mi R, Shah SP (2020) In situ-grown carbon nanotubes enhanced cement-based materials with multifunctionality. Cem Concr Compos 108 https://doi.org/10.1016/j.cemconcomp.2020. 103518

71. X. Wang, D. Feng, X. Shi, J. Zhong, Paste on Carbon Nanotube Sponge: A Platform to Investigate the Effects of Carbon Nanotube on the Nucleation of C3S Hydration, Cement and Concrete Research. Under review.

72. Lee C, Wei X, Kysar JW, Hone J (2008) Measurement of the elastic properties and intrinsic strength of monolayer graphene. Science 321(5887):385-388. https://doi.org/10.1126/science.1157996

73. Tung VC, Allen MJ, Yang Y, Kaner RB (2009) High-throughput solution processing of large-scale graphene. Nat Nanotechnol 4(1):25-29. https://doi.org/10.1038/nnano.2008.329

74. Zandiatashbar A, Lee GH, An SJ, Lee S, Mathew N, Terrones M, Hayashi T, Picu CR, Hone J, Koratkar N (2014) Effect of defects on the intrinsic strength and stiffness of graphene. Nat Commun 5:3186. https://doi. org/10.1038/ncomms4186

75. Lu Z, Yu J, Yao J, Hou D (2020) Experimental and molecular modeling of polyethylene fiber/cement interface strengthened by graphene oxide. Cem Concr Compos 112. https://doi.org/10.1016/j.cemconcomp.2020. 103676 
76. D. Lu, J. Zhong, X. Shi, Graphene oxide nano-engineers the interfacial transition zone on fine aggregate in cement composites, Cement and Concrete Composites. Under review.

77. Pan Z, He L, Qiu L, Korayem AH, Li G, Zhu JW, Collins F, Li D, Duan WH, Wang MC (2015) Mechanical properties and microstructure of a graphene oxide-cement composite. Cem Concr Compos 58:140-147. https://doi.org/10.1016/j.cemconcomp.2015.02.001

78. Qureshi TS, Panesar DK, Sidhureddy B, Chen A, Wood PC (2019) Nanocement composite with graphene oxide produced from epigenetic graphite deposit. Compos Part B 159:248-258. https://doi.org/10. 1016/j.compositesb.2018.09.095

79. Lv S, Liu J, Sun T, Ma Y, Zhou Q (2014) Effect of GO nanosheets on shapes of cement hydration crystals and their formation process. Constr Build Mater 64:231-239. https://doi.org/10.1016/j.conbuildmat.2014. 04.061

80. Lv S, Ma Y, Qiu C, Sun T, Liu J, Zhou Q (2013) Effect of graphene oxide nanosheets of microstructure and mechanical properties of cement composites. Constr Build Mater 49:121-127. https://doi.org/10.1016/j. conbuildmat.2013.08.022

81. Zhou G-X, Zhong J, Zhang H, Hu X, Wu J, Koratkar N, Shi X (2017) Influence of releasing graphene oxide into a clayey sand: physical and mechanical properties. RSC Adv 7(29):18060-18067. https://doi.org/10. 1039/c7ra01539a

82. Zhao L, Guo X, Liu Y, Ge C, Chen Z, Guo L, Shu X, Liu J (2018) Investigation of dispersion behavior of GO modified by different water reducing agents in cement pore solution. Carbon 127:255-269. https://doi.org/ 10.1016/j.carbon.2017.11.016

83. MacLeod AJN, Collins FG, Duan W (2021) Effects of carbon nanotubes on the early-age hydration kinetics of Portland cement using isothermal calorimetry. Cem Concr Compos 119. https://doi.org/10.1016/j. cemconcomp.2021.103994

84. Lu Z, Hou D, Hanif A, Hao W, Li Z, Sun G (2018) Comparative evaluation on the dispersion and stability of graphene oxide in water and cement pore solution by incorporating silica fume. Cem Concr Compos 94:33-42. https://doi.org/10.1016/j.cemconcomp.2018.08.011

85. Zhao L, Guo X, Liu Y, Ge C, Guo L, Shu X, Liu J (2017) Synergistic effects of silica nanoparticles/polycarboxylate superplasticizer modified graphene oxide on mechanical behavior and hydration process of cement composites. RSC Adv 7(27):16688-16702. https://doi.org/10.1039/c7ra0 $1716 b$

86. Hu M, Guo J, Fan J, Li P, Chen D (2019) Dispersion of triethanolaminefunctionalized graphene oxide (TEA-GO) in pore solution and its influence on hydration, mechanical behavior of cement composite. Constr Build Mater 216:128-136. https://doi.org/10.1016/j.conbuildmat.2019. 04.180

87. Imanian Ghazanlou S, Jalaly M, Sadeghzadeh S, Habibnejad Korayem A (2020) High-performance cement containing nanosized Fe3O4-decorated graphene oxide. Constr Build Mater:260. https://doi.org/10.1016/j. conbuildmat.2020.120454

88. Zhao L, Guo X, Ge C, Li Q, Guo L, Shu X, Liu J (2017) Mechanical behavior and toughening mechanism of polycarboxylate superplasticizer modified graphene oxide reinforced cement composites. Compos Part B 113:308-316. https://doi.org/10.1016/j.compositesb.2017.01.056

89. Jing G, Ye Z, Lu X, Hou P (2017) Effect of graphene nanoplatelets on hydration behaviour of Portland cement by thermal analysis. Adv Cem Res 29(2):63-70. https://doi.org/10.1680/jadcr.16.00087

90. Mohammed A, Sanjayan JG, Duan WH, Nazari A (2016) Graphene Oxide Impact on Hardened Cement Expressed in Enhanced Freeze-Thaw Resistance. J Mater Civ Eng 28(9). https://doi.org/10.1061/(asce)mt. 1943-5533.0001586

91. Silvestro L, Gleize PJP (2020) Effect of carbon nanotubes on compressive, flexural and tensile strengths of Portland cement-based materials: A systematic literature review. Constr Build Mater 264. https://doi.org/ 10.1016/j.conbuildmat.2020.120237

92. Jing G-j, Ye Z-m, Li C, Cui J, Wang S-x, Cheng X (2019) A ball milling strategy to disperse graphene oxide in cement composites. New Carbon Materials 34(6):569-577. https://doi.org/10.1016/s1872-5805(19) 60032-6

93. Jing G-j, Ye Z-m, Li C, Cui J, Wang S-x, Cheng X (2020) A ball milling strategy to disperse graphene oxide in cement composites. Carbon 159. https://doi.org/10.1016/j.carbon.2019.12.082
94. Akarsh PK, Marathe S, Bhat AK (2020) Influence of graphene oxide on properties of concrete in the presence of silica fumes and M-sand. Constr Build Mater. https://doi.org/10.1016/j.conbuildmat.2020.121093

95. Sanchez F, Ince C (2009) Microstructure and macroscopic properties of hybrid carbon nanofiber/silica fume cement composites. Compos Sci Technol 69(7-8):1310-1318. https://doi.org/10.1016/j.compscitech. 2009.03 .006

96. Yazdanbakhsh A, Grasley Z (2014) Utilization of Silica Fume to Stabilize the Dispersion of Carbon Nanofilaments in Cement Paste. J Mater Civ Eng 26(7). https://doi.org/10.1061/(asce)mt.1943-5533.0001016

97. Mowlaei R, Lin J, Basquiroto de Souza F, Fouladi A, Habibnejad Korayem A, Shamsaei E, Duan W (2021) The effects of graphene oxide-silica nanohybrids on the workability, hydration, and mechanical properties of Portland cement paste. Constr Build Mater 266. https://doi.org/10. 1016/j.conbuildmat.2020.121016

98. Zhao J, Wang Z, White JC, Xing B (2014) Graphene in the aquatic environment: adsorption, dispersion, toxicity and transformation. Environ Sci Technol 48(17):9995-10009. https://doi.org/10.1021/es5022679

99. Yan X, Zheng D, Yang H, Cui H, Monasterio M, Lo Y (2020) Study of optimizing graphene oxide dispersion and properties of the resulting cement mortars. Constr Build Mater 257. https://doi.org/10.1016/j. conbuildmat.2020.119477

100. Zhao L, Zhu S, Wu H, Zhang X, Tao Q, Song L, Song Y, Guo X (2020) Deep research about the mechanisms of graphene oxide (GO) aggregation in alkaline cement pore solution. Constr Build Mater 247. https://doi.org/ 10.1016/j.conbuildmat.2020.118446

101. Liu Y, Li Q-q, Zhang H, Yu S-p, Zhang L, Yang Y-z (2020) Research progress on the use of micro/nano carbon materials for antibacterial dressings. New Carbon Materials 35(4):323-335. https://doi.org/10. 1016/s1872-5805(20)60492-9

102. Wu Q, He J, Wang F, Yang X, Zhu J (2020) Comparative study on effects of covalent-covalent, covalent-ionic and ionic-ionic bonding of carbon fibers with polyether amine/GO on the interfacial adhesion of epoxy composites. Appl Surf Sci 532. https://doi.org/10.1016/j.apsusc.2020. 147359

103. Coleman JN, Khan U, Blau WJ, Gun'ko YK (2006) Small but strong: A review of the mechanical properties of carbon nanotube-polymer composites. Carbon 44(9):1624-1652. https://doi.org/10.1016/j.carbon. 2006.02.038

104. Wang Q, Wang J, Lu C-x, Liu B-w, Zhang K, Li C-z (2015) Influence of graphene oxide additions on the microstructure and mechanical strength of cement. Carbon 95:1083-1084. https://doi.org/10.1016/j.carbon. 2015.08.089

105. Lin J, Shamsaei E, Basquiroto de Souza F, Sagoe-Crentsil K, Duan WH (2020) Dispersion of graphene oxide-silica nanohybrids in alkaline environment for improving ordinary Portland cement composites. Cem Concr Compos 106. https://doi.org/10.1016/j.cemconcomp.2019. 103488

106. Shao H, Chen B, Li B, Tang S, Li Z (2017) Influence of dispersants on the properties of CNTs reinforced cement-based materials. Constr Build Mater 131:186-194. https://doi.org/10.1016/j.conbuildmat.2016.11.053

107. Xie Z, Zhou H, Li Q, He C, Zhang S, Li D (2020) Effects of colloidal nanosilica/polycarboxylate ether superplasticizer nanocomposite and graphene oxide on properties of fly ash blended cement. Constr Build Mater 262. https://doi.org/10.1016/j.conbuildmat.2020.120767

108. Papanikolaou I, Ribeiro de Souza L, Litina C, Al-Tabbaa A (2021) Investigation of the dispersion of multi-layer graphene nanoplatelets in cement composites using different superplasticiser treatments. Constr Build Mater 293. https://doi.org/10.1016/j.conbuildmat.2021.123543

109. Du H, Pang SD (2018) Dispersion and stability of graphene nanoplatelet in water and its influence on cement composites. Constr Build Mater 167:403-413. https://doi.org/10.1016/j.conbuildmat.2018.02.046

110. Ju L, Zhang W, Wang X, Hu J, Zhang Y (2012) Aggregation kinetics of SDBS-dispersed carbon nanotubes in different aqueous suspensions. Colloids Surf A Physicochem Eng Asp 409:159-166. https://doi.org/10. 1016/j.colsurfa.2012.06.015

111. Chowdhury I, Duch MC, Mansukhani ND, Hersam MC, Bouchard D (2013) Colloidal properties and stability of graphene oxide nanomaterials in the aquatic environment. Environ Sci Technol 47(12):6288-6296. https://doi.org/10.1021/es400483k 
112. Mohammed A, Sanjayan JG, Duan WH, Nazari A (2015) Incorporating graphene oxide in cement composites: A study of transport properties. Constr Build Mater 84:341-347. https://doi.org/10.1016/j.conbuildmat. 2015.01.083

113. Li X, Korayem AH, Li C, Liu Y, He H, Sanjayan JG, Duan WH (2016) Incorporation of graphene oxide and silica fume into cement paste: A study of dispersion and compressive strength. Constr Build Mater 123:327-335. https://doi.org/10.1016/j.conbuildmat.2016.07.022

114. Bai S, Jiang L, Xu N, Jin M, Jiang S (2018) Enhancement of mechanical and electrical properties of graphene/cement composite due to improved dispersion of graphene by addition of silica fume. Constr Build Mater 164:433-441. https://doi.org/10.1016/j.conbuildmat.2017. 12.176

115. Kim HK, Nam IW, Lee HK (2014) Enhanced effect of carbon nanotube on mechanical and electrical properties of cement composites by incorporation of silica fume. Compos Struct 107:60-69. https://doi.org/ 10.1016/j.compstruct.2013.07.042

116. Kothiyal NC, Sharma S, Mahajan S, Sethi S (2016) Characterization of reactive graphene oxide synthesized from ball-milled graphite: its enhanced reinforcing effects on cement nanocomposites. J Adhes Sci Technol 30(9):915-933. https://doi.org/10.1080/01694243.2015.11292 14

117. Ghosh S, Harish S, Rocky KA, Ohtaki M, Saha BB (2019) Graphene enhanced thermoelectric properties of cement based composites for building energy harvesting. Energy Buildings 202. https://doi.org/10. 1016/j.enbuild.2019.109419

118. Chiranjiakumari Devi S, Ahmad Khan R (2020) Influence of graphene oxide on sulfate attack and carbonation of concrete containing recycled concrete aggregate. Constr Build Mater 250. https://doi.org/10. 1016/j.conbuildmat.2020.118883

119. Muthu M, Ukrainczyk N, Koenders E (2020) Effect of graphene oxide dosage on the deterioration properties of cement pastes exposed to an intense nitric acid environment. Constr Build Mater. https://doi.org/10. 1016/j.conbuildmat.2020.121272

120. Kim GM, Kim YK, Kim YJ, Seo JH, Yang BJ, Lee HK (2019) Enhancement of the modulus of compression of calcium silicate hydrates via covalent synthesis of CNT and silica fume. Constr Build Mater 198:218-225. https://doi.org/10.1016/j.conbuildmat.2018.11.161

121. Kim GM, Yang BJ, Ryu GU, Lee HK (2016) The electrically conductive carbon nanotube (CNT)/cement composites for accelerated curing and thermal cracking reduction. Compos Struct 158:20-29. https://doi.org/ 10.1016/j.compstruct.2016.09.014

122. Lee HS, Balasubramanian B, Gopalakrishna GVT, Kwon S-J, Karthick SP, Saraswathy V (2018) Durability performance of CNT and nanosilica admixed cement mortar. Constr Build Mater 159:463-472. https://doi. org/10.1016/j.conbuildmat.2017.11.003

123. Wieslaw Kurdowski. Cement and Concrete Chemistry-Springer Netherlands. Springer. 2014

124. Baquerizo LG, Matschei T, Scrivener KL, Saeidpour M, Wadsö L (2015) Hydration states of AFm cement phases. Cem Concr Res 73:143-157. https://doi.org/10.1016/j.cemconres.2015.02.011

125. Meng W, Khayat KH (2016) Mechanical properties of ultra-high-performance concrete enhanced with graphite nanoplatelets and carbon nanofibers. Compos Part B 107:113-122. https://doi.org/10.1016/j. compositesb.2016.09.069

126. Krystek M, Pakulski D, Patroniak V, Gorski M, Szojda L, Ciesielski A, Samori P (2019) High-Performance Graphene-Based Cementitious Composites. Adv Sci (Weinh) 6(9):1801195. https://doi.org/10.1002/advs.201801195

127. Vallurupalli K, Meng W, Liu J, Khayat KH (2020) Effect of graphene oxide on rheology, hydration and strength development of cement paste. Constr Build Mater:265. https://doi.org/10.1016/j.conbuildmat.2020. 120311

128. Rehman SKU, Ibrahim Z, Memon S, Aunkor M, Javed MF, Mehmood K, Shah S (2018) Influence of Graphene Nanosheets on Rheology, Microstructure, Strength Development and Self-Sensing Properties of Cement Based Composites. Sustainability 10(3). https://doi.org/10. 3390/su10030822

129. Gong K, Pan Z, Korayem AH, Qiu L, Li D, Collins F, Wang CM, Duan WH (2015) Reinforcing Effects of Graphene Oxide on Portland Cement Paste. J Mater Civ Eng 27(2). https://doi.org/10.1061/(asce)mt.19435533.0001125
130. Kim JH, Yim HJ, Ferron RD (2016) In situ measurement of the rheological properties and agglomeration on cementitious pastes. J Rheol 60(4):695-704. https://doi.org/10.1122/1.4954251

131. Yang $\mathrm{H}$, Monasterio $M$, Cui $H$, Han N (2017) Experimental study of the effects of graphene oxide on microstructure and properties of cement paste composite. Compos A: Appl Sci Manuf 102:263-272. https://doi. org/10.1016/j.compositesa.2017.07.022

132. Cwirzen A, Habermehl-Cwirzen K, Penttala V (2008) Surface decoration of carbon nanotubes and mechanical properties of cement/carbon nanotube composites. Adv Cem Res 20(2):65-73. https://doi.org/10 1680/adcr.2008.20.2.65

133. Wang Q, Wang J, LV C-X, Cui X-y, Li S-y, Wang X (2016) Rheological behavior of fresh cement pastes with a graphene oxide additive. New Carbon Materials 31(6):574-584. https://doi.org/10.1016/s18725805(16)60033-1

134. Cui H, Luo C, Sang G, Jin Y, Dong Z, Bao X, Tang W (2020) Effect of carbon nanotubes on properties of alkali activated slag-A mechanistic study. J Clean Prod 245. https://doi.org/10.1016/j.jclepro.2019.119021

135. Li H, Ding S, Zhang L, Ouyang J, Han B (2021) Rheological behaviors of cement pastes with multi-layer graphene. Constr Build Mater:269. https://doi.org/10.1016/j.conbuildmat.2020.121327

136. Leonavičius D, Pundienè I, Pranckevičienè J, Kligys M (2020) Selection of superplasticisers for improving the rheological and mechanical properties of cement paste with CNTs. Constr Build Mater 253. https://doi.org/ 10.1016/j.conbuildmat.2020.119182

137. Del Carmen Camacho M, Galao O, Baeza FJ, Zornoza E, Garces P (2014) Mechanical Properties and Durability of CNT Cement Composites. Materials (Basel) 7(3):1640-1651. https://doi.org/10.3390/ma7031640

138. Wang B, Jiang R, Wu Z (2016) Investigation of the Mechanical Properties and Microstructure of Graphene Nanoplatelet-Cement Composite. Nanomaterials 6(11). https://doi.org/10.3390/nano6110200

139. Liu J, Fu J, Yang Y, Gu C (2019) Study on dispersion, mechanical and microstructure properties of cement paste incorporating graphene sheets. Constr Build Mater 199:1-11. https://doi.org/10.1016/j.conbu ildmat.2018.12.006

140. Xu J, Zhang D (2017) Pressure-sensitive properties of emulsion modified graphene nanoplatelets/cement composites. Cem Concr Compos 84:74-82. https://doi.org/10.1016/j.cemconcomp.2017.07.025

141. Qin R, Zhou A, Yu Z, Wang Q, Lau D (2021) Role of carbon nanotube in reinforcing cementitious materials: An experimental and coarsegrained molecular dynamics study. Cem Concr Res 147. https://doi.org/ 10.1016/j.cemconres.2021.106517

142. Abrishami ME, Zahabi V (2016) Reinforcing graphene oxide/cement composite with NH2 functionalizing group. Bull Mater Sci 39(4):10731078. https://doi.org/10.1007/s12034-016-1250-7

143. Matalkah F, Soroushian P (2020) Graphene nanoplatelet for enhancement the mechanical properties and durability characteristics of alkali activated binder. Constr Build Mater, 249. https://doi.org/10.1016/j. conbuildmat.2020.118773

144. Zhu X, Gao Y, Dai Z, Corr DJ, Shah SP (2018) Effect of interfacial transition zone on the Young's modulus of carbon nanofiber reinforced cement concrete. Cem Concr Res 107:49-63. https://doi.org/10.1016/j. cemconres.2018.02.014

145. Guo L, Wu J, Wang H (2020) Mechanical and perceptual characterization of ultra-high-performance cement-based composites with silanetreated graphene nano-platelets. Constr Build Mater 240. https://doi. org/10.1016/j.conbuildmat.2019.117926

146. Cui H, Yan X, Tang L, Xing F (2017) Possible pitfall in sample preparation for SEM analysis - A discussion of the paper "Fabrication of polycarboxylate/graphene oxide nanosheet composites by copolymerization for reinforcing and toughening cement composites" by Lv et al. Cem Concr Compos 77:81-85. https://doi.org/10.1016/j.cemconcomp.2016.12.007

147. Konstantopoulos G, Koumoulos E, Karatza A, Charitidis C (2020) Pore and phase identification through nanoindentation mapping and micro-computed tomography in nanoenhanced cement. Cem Concr Compos 114. https://doi.org/10.1016/j.cemconcomp.2020.103741

148. Sun G, Liang R, Lu Z, Zhang J, Li Z (2016) Mechanism of cement/carbon nanotube composites with enhanced mechanical properties achieved by interfacial strengthening. Constr Build Mater 115:87-92. https://doi. org/10.1016/j.conbuildmat.2016.04.034 
149. Tian W, Liu Y, Qi B, Wang W (2021) Enhanced effect of carbon nanofibers on heating efficiency of conductive cementitious composites under ohmic heating curing. Cem Concr Compos 117. https://doi.org/10. 1016/j.cemconcomp.2020.103904

150. Han B, Yang Z, Shi X, Yu X (2012) Transport Properties of Carbon-Nanotube/Cement Composites. J Mater Eng Perform 22(1):184-189. https:// doi.org/10.1007/s11665-012-0228-x

151. Xie T, Fang C, Mohamad Ali MS, Visintin P (2018) Characterizations of autogenous and drying shrinkage of ultra-high performance concrete (UHPC): An experimental study. Cem Concr Compos 91:156-173. https://doi.org/10.1016/j.cemconcomp.2018.05.009

152. Yu J, Zheng Q, Hou D, Zhang J, Li S, Jin Z, Wang P, Yin B, Wang X (2019) Insights on the capillary transport mechanism in the sustainable cement hydrate impregnated with graphene oxide and epoxy composite. Compos Part B 173. https://doi.org/10.1016/j.compositesb.2019. 106907

153. Qureshi TS, Panesar DK (2019) Impact of graphene oxide and highly reduced graphene oxide on cement based composites. Constr Build Mater 206:71-83. https://doi.org/10.1016/j.conbuildmat.2019.01.176

154. Muthu M, Santhanam M (2018) Effect of reduced graphene oxide, alumina and silica nanoparticles on the deterioration characteristics of Portland cement paste exposed to acidic environment. Cem Concr Compos 91:118-137. https://doi.org/10.1016/j.cemconcomp.2018.05. 005

155. Mohammed A, Sanjayan JG, Nazari A, Al-Saadi NTK (2018) The role of graphene oxide in limited long-term carbonation of cement-based matrix. Constr Build Mater 168:858-866. https://doi.org/10.1016/j. conbuildmat.2018.02.082

156. Lu D, Shi X, Zhong J (2022) Understanding the role of unzipped carbon nanotubes in cement pastes. Cem Concr Compos 126. https://doi.org/ 10.1016/j.cemconcomp.2021.104366

\section{Publisher's Note}

Springer Nature remains neutral with regard to jurisdictional claims in published maps and institutional affiliations.

\section{Submit your manuscript to a SpringerOpen ${ }^{\circ}$ journal and benefit from:}

- Convenient online submission

- Rigorous peer review

- Open access: articles freely available online

- High visibility within the field

- Retaining the copyright to your article

Submit your next manuscript at $\gg$ springeropen.com 